\title{
Water in cratonic lithosphere: Calibrating laboratory- determined models of electrical conductivity of mantle minerals using geophysical and petrological observations
}

\author{
Alan G. Jones \\ Dublin Institute for Advanced Studies, 5 Merrion Square, Dublin 2, Ireland (alan@cp.dias.ie)
}

Javier Fullea

Dublin Institute for Advanced Studies, 5 Merrion Square, Dublin 2, Ireland

Now at Institute of Geosciences, CSIC-UCM, ES-28040 Madrid, Spain

Rob L. Evans

Woods Hole Oceanographic Institution, Woods Hole, Massachusetts 02543, USA

Mark R. Muller

Dublin Institute for Advanced Studies, 5 Merrion Square, Dublin 2, Ireland

[1] Measurements of electrical conductivity of "slightly damp" mantle minerals from different laboratories are inconsistent, requiring geophysicists to make choices between them when interpreting their electrical observations. These choices lead to dramatically different conclusions about the amount of water in the mantle, resulting in conflicting conclusions regarding rheological conditions; this impacts on our understanding of mantle convection, among other processes. To attempt to reconcile these differences, we test the laboratory-derived proton conduction models by choosing the simplest petrological scenario possible cratonic lithosphere - from two locations in southern Africa where we have the most complete knowledge. We compare and contrast the models with field observations of electrical conductivity and of the amount of water in olivine and show that none of the models for proton conduction in olivine proposed by three laboratories are consistent with the field observations. We derive statistically model parameters of the general proton conduction equation that satisfy the observations. The pre-exponent dry proton conduction term $\left(\sigma_{0}\right)$ and the activation enthalpy $\left(\Delta H_{w e t}\right)$ are derived with tight bounds, and are both within the broader $2 \sigma$ errors of the different laboratory measurements. The two other terms used by the experimentalists, one to describe proton hopping (exponent $r$ on pre-exponent water content $C_{w}$ ) and the other to describe $\mathrm{H}_{2} \mathrm{O}$ concentration-dependent activation enthalpy (term $\alpha C_{w}^{1 / 3}$ added to the activation energy), are less well defined and further field geophysical and petrological observations are required, especially in regions of higher temperature and higher water content.

Components: 16,500 words, 8 figures, 9 tables.

Keywords: Kaapvaal craton; Rehoboth terrane; mantle water.

Index Terms: 7218 Seismology: Lithosphere (1236); 7831 Space Plasma Physics: Laboratory studies and experimental techniques.

Received 17 January 2012; Revised 30 April 2012; Accepted 30 April 2012; Published 14 June 2012. 
Jones, A. G., J. Fullea, R. L. Evans, and M. R. Muller (2012), Water in cratonic lithosphere: Calibrating laboratory-determined models of electrical conductivity of mantle minerals using geophysical and petrological observations, Geochem. Geophys. Geosyst., 13, Q06010, doi:10.1029/2012GC004055.

\section{Introduction}

[2] Water within the "solid" Earth has played, and continues to play, a dominant role in shaping our planet [Hirschmann and Kohlstedt, 2012]. Yet, despite the amount of water in the mantle being estimated to be of order of that in the hydrosphere [Bell and Rossman, 1992; Ingrin and Skogby, 2000], we know surprisingly little about its distribution. It is only within the last two to three decades that mineral physicists have established that most nominally anhydrous minerals (NAMs) can absorb water, or rather hydroxyl, to levels of up to some hundreds ppm (see special issue of Reviews of Mineralogy and Geochemistry, 62, 2006 [Keppler and Smyth, 2006]), since the original proposal by Martin and Donnay [1972] and the landmark experiments by Bai and Kohlstedt [1992] (see News and Views comment by Bell [1992]). The presence of water in NAMs has a disproportionately large effect on many crucial physical and chemical properties of mantle minerals [e.g., Thompson, 1992; Hirth and Kohlstedt, 1996; Williams and Hemley, 2001; Peslier, 2010], such as enhancing electrical conductivity [e.g., Karato, 1990], modifying seismic properties [e.g., Jung and Karato, 2001; Karato, 2006], reducing strength [e.g., Karato et al., 1986] and viscosity [e.g., Hirth and Kohlstedt, 1996], facilitating mineral deformation [e.g., Mackwell et al., 1985], lowering the peridotite solidus [e.g., Gaetani and Grove, 1998], and increasing the diffusion rate of other ionic species [e.g., Hier-Majumder et al., 2005]. The presence of hydroxyl point defects in NAMs weakens the Si-O bonds consequently affecting elastic properties, phase equilibria, transport properties and particularly electrical conductivity and viscosity [e.g., Du Frane and Tyburczy, 2012]. Thus, besides other concerns, geodynamic mantle convection models of our planet are totally reliant on geophysical observations to constrain a largely poorly known, and difficult to know, quantity, but one that critically controls many bulk physical properties. Li et al. [2008] undertook a petrological study of the water content in mantle minerals from xenoliths sourced in lithosphere beneath the Colorado Plateau and southern Basin and Range, and found highest water contents for Colorado Plateau lithosphere and virtually dry olivine beneath San Carlos in the Basin and Range. They interpret their results in terms of implications for viscosity and the recycling of cratonic material. Their paper makes for an excellent tutorial on intricacies of laboratory determination of water content in mantle samples.

[3] As an illustration of the difficulty of remote sensing of water in the mantle using seismology, and pointed out by Karato [2011], different seismic techniques can infer opposing results; the global surface wave study of Meier et al. [2009] suggests that the mantle transition zone (MTZ) beneath eastern Asia is water-poor, whereas the compressional body wave study of Suetsugu et al. [2006] infers that the MTZ is water-rich in the very same region. This dichotomy is not surprising given that water in NAMs reduces seismic velocity by marginally detectable amounts; $1 \mathrm{wt} \%$ water $(10,000 \mathrm{ppm})$ reduces velocity by only $\sim 1 \%$ [Karato, 2006].

[4] The longevity of ancient cratonic lithosphere has been attributed, in part, to internal strength arising from a largely dry composition. Yet petrological evidence is accumulating that, contrary to previously widely held opinion, there is indeed water in NAMs of cratonic lithosphere, at least in its upper part above $\sim 150 \mathrm{~km}$ (coincidently, the approximate depth of the graphite-diamond stability boundary another important interface for electromagnetic observations). Peslier et al. [2010b] report water contents in olivines of the order of $60-100 \mathrm{ppm}$ in upper mantle lithosphere, with virtually dry olivine in the lower lithosphere, for four regions of the Kaapvaal Craton (the Kimberley region, Jagersfontein, Finch, and Lesotho), based on examination of xenoliths exhumed in kimberlites. This observation is substantiated by a recent study [Baptiste et al., 2012]. Here, we examine whether geophysical observations coupled with laboratory studies support this petrological view, or rather, we take the geophysical observations and the petrological information to test the laboratory-determined parametric descriptions and model parameters.

[5] Deep-probing electromagnetic observations have the potential to image the existence and distribution of water [Karato, 2006], and can significantly contribute to this debate on water in the mantle. Electrical conductivity is a key and unique parameter for detecting water in the mantle, but is somewhat neglected by the geoscientific community. Recent attempts have been made to use laboratory measurements coupled with EM observations 
Table 1. Parameters for Proton Conduction (Equation (1)) in Hydrous Olivine From Three Different Laboratories and Derived Herein ${ }^{\mathrm{a}}$

\begin{tabular}{|c|c|c|c|c|c|}
\hline Reference & $\log _{10}\left(\sigma_{0}[\mathrm{~S} / \mathrm{m}]\right)$ & $\mathrm{r}$ & $\Delta \mathrm{H}_{\text {wet }}(\mathrm{eV})$ & $\alpha$ & Comments \\
\hline Wang et al. [2006] & $3.00 \pm \mathbf{0 . 4}$ & $0.62 \pm 0.15$ & $\mathbf{0 . 8 7} \pm \mathbf{0 . 0 5}$ & 0 & \\
\hline Yoshino et al. [2009] & $1.90 \pm 0.44$ & 1 & $0.92 \pm 0.04$ & $0.16 \pm 0.02$ & \\
\hline Poe et al. [2010] & $2.59 \pm 0.16$ & 1 & $1.26 \pm 0.04$ & $1.18 \pm 0.04$ & {$\left[\begin{array}{lll}1 & 0 & 0\end{array}\right]$ axis } \\
\hline Poe et al. [2010] & $3.46 \pm 0.09$ & 1 & $1.50 \pm 0.05$ & $1.43 \pm 0.11$ & {$\left[\begin{array}{lll}0 & 1 & 0\end{array}\right]$ axis } \\
\hline Poe et al. [2010] & $1.02 \pm 0.09$ & 1 & $0.812 \pm 0.016$ & $0.70 \pm 0.015$ & {$\left[\begin{array}{lll}0 & 0 & 1\end{array}\right]$ axis } \\
\hline Fullea et al. [2011] & $2.35 \pm \mathbf{0 . 1 1}$ & 1 & $1.19 \pm \mathbf{0 . 0 3 5}$ & $1.10 \pm 0.055$ & $\begin{array}{l}\text { Arithmetic averages of values } \\
\text { of Poe et al. [2010] }\end{array}$ \\
\hline Revised Karato & $2.70 \pm 0.26$ & $\mathbf{0 . 7 0} \pm \mathbf{0 . 1 2}$ & $\mathbf{0 . 9 1} \pm \mathbf{0 . 0 4}$ & 0 & \\
\hline Proposed herein & $3.05 \pm 0.16$ & $\mathbf{0 . 8 6} \pm \mathbf{0 . 0 8}$ & $\mathbf{0 . 9 1} \pm \mathbf{0 . 0 3}$ & $\mathbf{0 . 0 9} \pm \mathbf{0 . 0 8}$ & \\
\hline
\end{tabular}

${ }^{a}$ Refer to the text for derivations of the "Revised Karato" and "Proposed" parameterizations. The values from Poe et al. [2010, Table 3] have been converted from wt ppm water to wt \%. For $\sigma_{0}$ this means multiplying by $10^{4}$ then taking the base- 10 logarithm. For $\alpha$ this means multiplying by 21.54 (i.e., $\left.\left(10^{4}\right)^{1 / 3}\right)$. Italic values are implicit. Bold values are used herein.

to define the water content of the mantle [Khan et al., 2011; Khan and Shankland, 2012]. However, the EM observations must be carefully calibrated by laboratory measurements and, equally as importantly, vice versa.

[6] To perform the latter of these, we compare laboratory measurements of the electrical conductivity of hydrous mantle minerals, particularly olivine, with magnetotelluric observations from two locations in southern Africa where there is xenolith control on composition, water concentration (at one of the locations) and reasonable estimates of probable present-day temperature. We focus on petrological and electromagnetic observations at a depth of $100 \mathrm{~km}$ for our study. The choice of this depth is primarily based on optimizing the sensitivity of MT data to absolute resistivity in a moderately resistive mantle beneath a typically conductive crust. By $100 \mathrm{~km}$, the effects of the crustal attenuation are reduced and the true resistivity can usually be resolved [see Jones, 1999, Figure 3]. In Southern Africa, crustal conductivity is nowhere as high as that in Jones [1999, Figure 3], so superior resolution of mantle resistivity is expected (discussed below).

\section{Proton Conduction in Hydrous Olivine}

[7] Three laboratories, namely those of S.-I. Karato [Wang et al., 2006], T. Yoshino [Yoshino et al., 2009] and B. Poe [Poe et al., 2010], have recently undertaken the very difficult and tedious experiments, and have reported electrical conductivity measurements on hydrous olivine. They and fit their experimental data to an Arrhenius equation of the general form

$$
\sigma_{p}=\sigma_{0} C_{w}^{r} \exp \left(\frac{-\left(\Delta H_{w e t}-\alpha C_{w}^{1 / 3}\right)}{k T}\right),
$$

where $k$ is Boltzmann's constant, $T$ is temperature (in Kelvin), $\sigma_{0}$ is the pre-exponent dry proton conduction term (in $\mathrm{S} / \mathrm{m}$, usually given in terms of its base- 10 $\operatorname{logarithm}$ ), $C_{w}$ is the water content (in wt ppm $\mathrm{H}_{2} \mathrm{O}$ ), and $\Delta H_{\text {wet }}$ is the activation enthalpy (in $\mathrm{eV}$ ). The power term $r$ on the pre-exponent water content $C_{w}$ is used by the Karato group to describe proton hopping [Karato, 2006], and ranges from 0.50 to 0.75 ; it is unused (i.e., set to 1) by the Yoshino and Poe groups. The $\alpha C_{w}^{1 / 3}$ term is used by the Yoshino and Poe groups to describe $\mathrm{H}_{2} \mathrm{O}$ concentration-dependent activation enthalpy, with the factor of $1 / 3$ on $C_{w}$ arising from the water activation enthalpy being expected to be proportional to the cubic root of the proton concentration. This term is unused (i.e., $\alpha$ set to 0 ) by the Karato group and by some other groups who fit models of the form of equation (1) to their data (discussed below). Poe et al. [2010] demonstrate the superiority of fit they obtained by including this $\alpha$ term in "wetter" conditions, i.e., for higher water contents of the order of hundreds to thousands of ppm. The values of the model parameters that the three laboratories report best fit their data are given in Table 1, together with determined errors on each parameter.

[8] There is complete agreement between the three laboratories that water significantly enhances the electrical conductivity of hydrous olivine in the mantle by orders of magnitude, but there is strong disagreement about both the strength of the contribution and the mechanism(s) [Huang et al., 2005; Wang et al., 2006; Yoshino et al., 2006; Manthilake et al., 2009; Poe et al., 2010]. Significant debate exists between the groups about their differing results, ranging from experimental procedure to sample handling to data analysis [Karato and Dai, 2009; Yoshino and Katsura, 2009; Yoshino, 2010; Karato, 2011; Karato and Wang, 2012], that are, for the most part, beyond the abilities of the 
Proton conduction conductivity at $800 \mathrm{C}$ for various water models

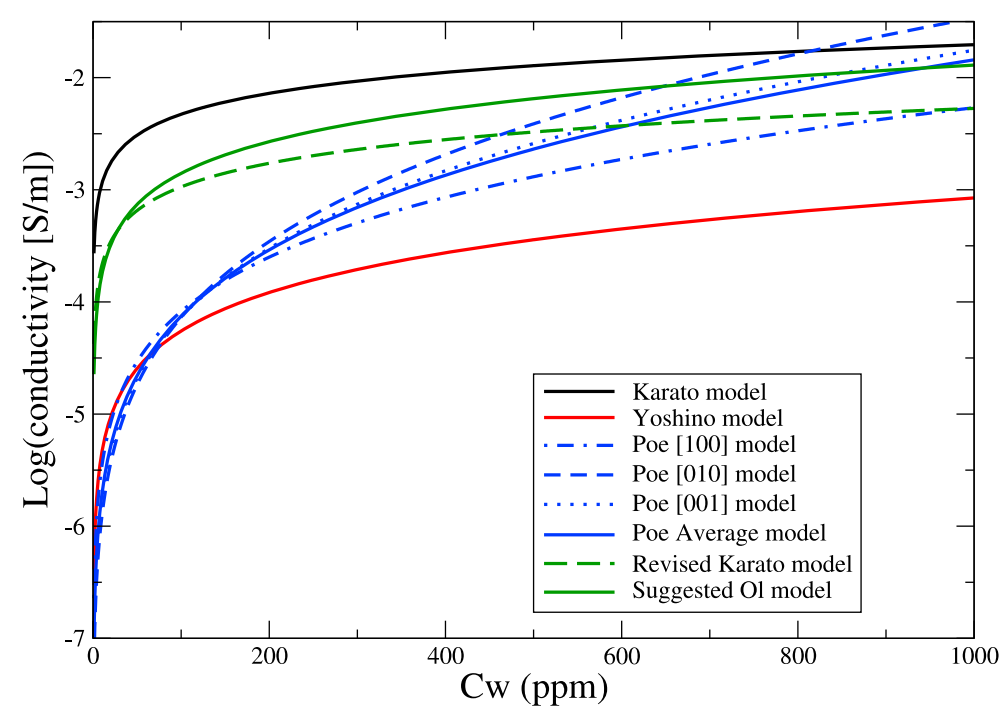

Figure 1. Proton conduction conductivity in olivine with varying water content (in ppm), from completely dry $(0 \mathrm{ppm})$ to wet $(1,000 \mathrm{ppm})$ at a temperature of $800^{\circ} \mathrm{C}$ for the three published models of Karato (black line), Yoshino (red line) and Poe (blue lines for along the three crystallographic axes and the average) derived using equation (1) with parameters from Table 1. The revised Karato model (dashed green line) and model proposed herein (solid green line) are also shown (although the latter has only been calibrated in the vicinity of $80 \mathrm{ppm}$ ).

majority of non-specialists to fully appreciate and discriminate between.

[9] Poe et al. [2010] measured electrical conductivity along the three crystallographic axes, and noted electrical anisotropy that increases with increasing water content. Electrical anisotropy, while highly important and a likely indicator of lithospheric fabric and anisotropic flow [Eaton and Jones, 2006], is not considered further herein as the differences in conductivity between the three crystallographic directions are far smaller than the differences between the three laboratories (see Figure 1).

[10] Figure 1 shows the variation of protonconduction conductivity with water content, from 0 to $1000 \mathrm{ppm}$, given by equation (1) with the parameters in Table 1 for a temperature of $800^{\circ} \mathrm{C}$. (Note that the Poe measurements [Poe et al., 2010] were made on olivines with higher water contents, from 360 to $2,000 \mathrm{ppm}$, compared to the Karato [Wang et al., 2006] (predominantly 100-200 ppm) and Yoshino [Yoshino et al., 2009] (all <200 ppm and mostly $<100 \mathrm{ppm}$ ) ones, and have been extrapolated down to lower water contents using their derived model parameters listed in Table 1.) At low water contents, below 200 ppm, inferred electrical anisotropy is low and the Yoshino and Poe models are in good agreement, but are two orders of magnitude less conductive (more resistive) than the Karato model (Figure 1). As water content increases, anisotropy effects increase in the Poe model, and the Poe conductivities, both individual and average, asymptotically approach the Karato model conductivity, whereas the Yoshino model conductivity remains less conductive than the Karato model conductivity by over 1.5 orders of magnitude (Figure 1). In the following, the "Poe" model refers to the averaged model defined by arithmetically averaging the Poe et al. [2010] parameters listed in Table 1 as used recently by Fullea et al. [2011].

[11] Each of the laboratories derives the errors associated with their model fits to their data, and those errors in the model parameters are listed in Table 1. The possible ranges of permitted conductivities within one sigma from the mean values can be explored by allowing each parameter to maximize or minimize within its one sigma bounds (Figure 2). For the Karato model parameters and defined errors (Figure 2a), the minimum conductivity is given by the lower bound of the preexponent conductivity $\sigma_{0}$, whereas the maximum conductivity over much of the water content range is given by the lower bound of the activation enthalpy $\Delta H_{\text {wet }}$. The maximum range between these minimum and maximum estimates is of order $0.40 \log$ units. For the Yoshino parameters and 

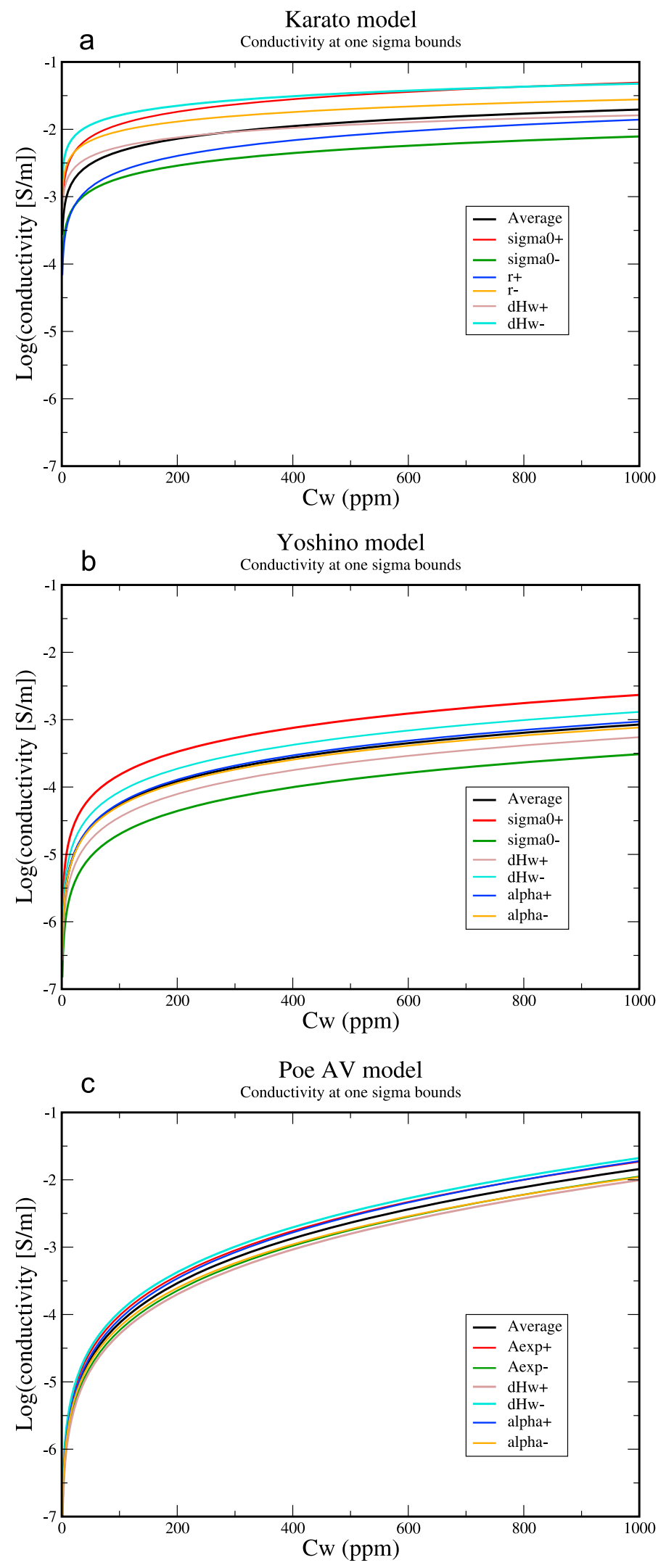

Figure 2. Conductivities from the three models at the bound limits for each of the model parameters (see Table 1). (a) Conductivities for the Karato model varying $\sigma_{0}, r$ and $\Delta H_{\text {wet }}$ to their respective bounds. Conductivities for the (b) Yoshino and (c) Poe models varying $\sigma_{0}, \Delta H_{\text {wet }}$ and $\alpha$ to their respective bounds. 
errors (Figure 2b), the upper and lower conductivity bounds are given by the upper and lower bounds of the pre-exponent conductivity $\sigma_{0}$ and the maximum range is also of order half an order of magnitude (0.44 log units). Note that the error in $\alpha$ has little effect on conductivity estimation in the Yoshino model; this is because $\alpha$ is almost negligibly small. For the Poe averaged parameters (Figure 2c), with its more tightly defined errors, the bounds are given by the bounds on the activation enthalpy. Here the maximum range is smaller and of order $0.16 \mathrm{log}$ units.

[12] If observations of electrical conductivity are to be used to constrain the amount of water present in the mantle, then there has to be resolution of the differences between these disparate laboratory data sets, especially at the lower water contents inferred for cratonic lithosphere.

\subsection{Sensitivity to Amount of Water}

[13] Given its high sensitivity, the presence or absence of water is easily determined from the observed electrical conductivity, but sensitivity to the amount of water is given by the gradient of the curve of conductivity against increasing water content. For the Karato water model, $\sigma_{p, K}$, proton conductivity is given by

$$
\sigma_{\mathrm{p}, \mathrm{K}}=\sigma_{0} C_{W}^{r} \exp \left(\frac{-\Delta H_{\text {wet }}}{k T}\right)
$$

and its derivative with respect to water content, $C_{w}$, is

$$
\frac{\delta \sigma_{\mathrm{p}, \mathrm{K}}}{\delta C_{W}}=\sigma_{0} r C_{W}^{r-1} \exp \left(\frac{-\Delta H_{w e t}}{k T}\right) .
$$

For olivine, $\sigma_{0}=10^{3.0}, r=0.62$, and $\Delta H_{\text {wet }}=0.90$, and thus

$$
\sigma_{\mathrm{p}, \mathrm{K}}(\mathrm{ol})=10^{3.0} C_{W}^{0.62} \exp \left(\frac{-0.90}{k T}\right)
$$

and its derivative with respect to changing water content is simply

$$
\frac{\delta \sigma_{\mathrm{p}, \mathrm{K}}(\mathrm{ol})}{\delta C_{W}}=10^{3.0} 0.62 C_{W}^{-0.38} \exp \left(\frac{-0.90}{k T}\right),
$$

i.e., the gradient is inversely dependent on the water content (to the power 0.38), and inversely exponentially dependent on temperature. The gradient is only weakly dependent on water content, but is greatly dependent on temperature. For the Yoshino and Poe proton conductivity models, the exponent $r$ on $C_{w}$ is taken to be unity, and the general form of their model is

$$
\sigma_{p, Y P}=\sigma_{0} C_{w} \exp \left(\frac{-\left(\Delta H_{w e t}-\alpha C_{w}^{1 / 3}\right)}{k T}\right) .
$$

The gradient of this formula with respect to water content is

$$
\begin{aligned}
\frac{\delta \sigma_{\mathrm{p}, \mathrm{YP}}}{\delta C_{W}}= & \sigma_{0} \exp \left(\frac{-\Delta H_{w e t}}{k T}\right)\left(\exp \left(\frac{\alpha C_{w}^{1 / 3}}{k T}\right)\right. \\
& \left.+\frac{1}{3} \frac{\alpha C_{w}^{1 / 3}}{k T} \exp \left(\frac{\alpha C_{w}^{1 / 3}}{k T}\right)\right), \\
= & \sigma_{0}\left(1+\frac{\alpha C_{w}^{1 / 3}}{3 k T}\right) \exp \left(\frac{-\left(\Delta H_{w e t}-\alpha C_{w}^{1 / 3}\right)}{k T}\right) .
\end{aligned}
$$

For the low water contents and the temperatures considered here, i.e., $C_{w}$ of order $100 \mathrm{ppm}$ and $T \sim$ $800^{\circ} \mathrm{C}$, the term $C_{w}^{1 / 3} / 3 k T$ becomes of order one, and thus the second term in the pre-exponent brackets becomes of order $\alpha$. Substituting the values for olivine for the Yoshino and Poe models (Table 1) in equation (7) yields

$\frac{\delta \sigma_{\mathrm{p}, \mathrm{Y}}(\mathrm{ol})}{\delta C_{W}}=10^{1.90}\left(1+\frac{0.16 C_{w}^{1 / 3}}{3 k T}\right) \exp \left(\frac{-\left(0.92-0.16 C_{w}^{1 / 3}\right)}{k T}\right)$,

and

$\frac{\delta \sigma_{\mathrm{p}, \mathrm{P}}(\mathrm{ol})}{\delta C_{W}}=10^{2.35}\left(1+\frac{1.10 C_{w}^{1 / 3}}{3 k T}\right) \exp \left(\frac{-\left(1.19-1.10 C_{w}^{1 / 3}\right)}{k T}\right)$.

For the Yoshino model, the $\alpha$ term is small and thus the gradient is only weakly dependent on water content. In contrast, for the Poe model the $\alpha$ term is large which results in a gradient that is strongly dependent on water content.

[14] The changes expected in conductivity when the water content is doubled are shown in Figure 3 for the three water models. Given these gradient considerations, if either the Karato or Yoshino model is correct, then MT studies will be able to detect the presence of water, but will be virtually insensitive to its amount. In contrast, if the Poe model is correct, then, provided there is good temperature control (to better than $100^{\circ} \mathrm{C}$, see below), MT data can be used not only to detect the presence of water, but also to define the amount of water in lithospheric mantle.

\section{Proton Conduction in Hydrous Pyroxenes}

[15] Proton conduction observations in hydrous Opx have been reported by Karato's lab [Dai and 


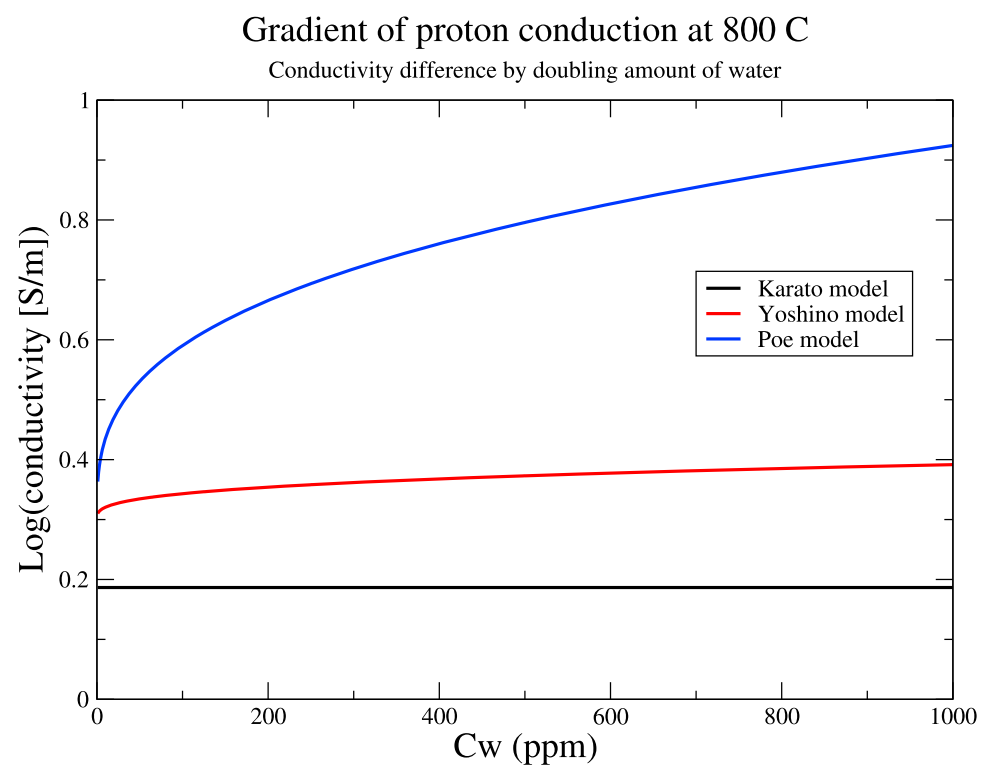

Figure 3. Sensitivity of water models to amount of water. Shown are the changes in the logarithm (base10) of conductivity $[\mathrm{S} / \mathrm{m}]$ when doubling the amount of water for the Karato (black), Yoshino (red) and averaged Poe (blue) water models.

Karato, 2009] (Table 2), and the model values fitting equation (1) (with $\alpha=0$ ) are used for Opx and Cpx calculations for Karato model calculations and our own. Recent papers from Yang et al. [Yang et al., 2011, 2012; Yang and McCammon, 2012] list model values fitting equation (1) (again with $\alpha=0$ ) for hydrous Opx and Cpx (Table 2), but use lower crustal material with high iron content, thus the pre-exponent term is higher, by an order of magnitude, than that of Dai and Karato [2009].

[16] Following Fullea et al. [2011], for the Yoshino and Poe model calculations we adopt the same values for Opx and Cpx as the Poe averaged olivine values. We note that model values for Ol from Karato's lab are not too dissimilar from their model values for
Opx and Gt, hence we assume that Yoshino and Poe's labs would have similar values for Opx and $\mathrm{Cpx}$, were they to measure them, as they do for $\mathrm{Ol}$.

[17] Errors in the model parameters for Cpx are negligible, given the very low $\mathrm{Cpx}$ content in the samples we take as representative of the two kimberlite fields.

\section{Jagersfontein and Gibeon Xenolith Information}

\subsection{Composition}

[18] For petrological characterization of the lithosphere at $100 \mathrm{~km}$ beneath southern Africa, we take

Table 2. Parameters for Proton Conduction in Hydrous Pyroxenes ${ }^{\mathrm{a}}$

\begin{tabular}{|c|c|c|c|c|c|}
\hline Reference & $\log _{10}\left(\sigma_{0}[\mathrm{~S} / \mathrm{m}]\right)$ & $\mathrm{r}$ & $\Delta \mathrm{H}_{\mathrm{wet}}(\mathrm{eV})$ & $\alpha$ & Comments \\
\hline Dai and Karato [2009]: Opx & 2.60 & 0.62 & 0.85 & 0 & $\begin{array}{l}\text { Used for Karato model calculations } \\
\text { and our own model for both } \\
\text { Opx and Cpx }\end{array}$ \\
\hline Yang et al. [2012]: Opx & $3.83 \pm 0.10$ & $0.90 \pm 0.04$ & $0.84 \pm 0.01$ & 0 & $\begin{array}{l}\text { Lower crustal xenolith material with } \\
\text { high Fe content }\end{array}$ \\
\hline Yang and McCammon [2012]: Cpx & $3.62 \pm 0.17$ & $1.035 \pm 0.08$ & $0.75 \pm 0.10$ & 0 & $\begin{array}{l}\text { Averages of model parameters from } \\
\text { two samples, High ferric content } \\
\text { in samples }\end{array}$ \\
\hline Yang et al. [2011]: Cpx & $3.56 \pm 0.10$ & $1.13 \pm 0.05$ & $0.74 \pm 0.01$ & 0 & $\begin{array}{l}\text { Lower crustal xenolith material with } \\
\text { high Fe content }\end{array}$ \\
\hline Yoshino and Poe model calculations & 2.35 & 1 & 1.19 & 1.10 & $\begin{array}{l}\text { Adopted the averaged Ol values of } \\
\text { Poe et al. [2010], as used by } \\
\text { Fullea et al. [2011] }\end{array}$ \\
\hline
\end{tabular}

${ }^{\mathrm{a}}$ Italic values are implicit. Bold values are used herein. 
Table 3. Whole Rock Mg\#, Modal Composition, and Petrologically Determined Pressures and Temperatures (at Eruption Age) of Four Xenoliths From the Jagersfontein (FRB Samples) and Gibeon (KGG Samples) Kimberlite Fields (Taken From James et al. [2004]), Plus Locality Averages

\begin{tabular}{llllllllll}
\hline Sample & Mg\# & Ol (\%) & Opx (\%) & Cpx (\%) & Gt (\%) & Sp (\%) & P (kbar) & T $\left({ }^{\circ} \mathrm{C}\right)$ & Depth $(\mathrm{km})$ \\
\hline FRB983 & 93.2 & 68.72 & 24.50 & 4.24 & 0.91 & 0.32 & 30.5 & 760 & 98 \\
FRB1007 & 93.2 & 70.28 & 23.84 & 2.56 & 1.79 & 0.32 & 33.1 & 804 & 106 \\
FRB AV & 93.2 & 69.50 & 24.17 & 3.40 & 1.35 & 0.32 & 31.8 & 782 & 102 \\
KGG06 & 91.19 & 73 & 11 & 9 & 8 & 0 & 33.2 & 926 & 108 \\
KGG65 & 92.30 & 76 & 12 & 4 & 7 & 0 & 33.5 & 872 & 109 \\
KGG AV & 91.75 & 74.5 & 11.5 & 6.5 & 7.5 & 0 & 33.35 & 899 & 108.5 \\
\hline
\end{tabular}

as representative xenolith information from two kimberlite fields, namely (1) Jagersfontein in the western Witwatersrand Block of the Kaapvaal Craton, and (2) the Gibeon field in central Namibia on the Rehoboth terrane. The kimberlites in these fields are both classified as Type I, and geochronology on the xenoliths gives Cretaceous eruption ages of some $86 \mathrm{Ma}$ [Smith, 1983] and 71.575.1 Ma [Kurszlaukis et al., 1998] for Jagersfontein and Gibeon respectively. The xenolith mineralogy data used here are given in James et al. [2004], and we pick two representative low-temperature, garnet lherzolite xenoliths from each kimberlite field that yield depth estimates close to $100 \mathrm{~km}$, based on the MacGregor [1974] geobarometer. Modal compositions are listed in Table 3, as well as in situ temperature estimates, based on the O'Neill and Wood [1979] geothermometer. The rationale for choosing these geobarometers and geothermometers over the plethora available [see, e.g., Nimis and Grutter, 2010] is given in James et al. [2004].

\subsection{Temperature Estimates}

[19] We recognize that the now-outdated O'Neill and Wood [1979] geothermometer can be in error by, in extreme cases, up to $200^{\circ} \mathrm{C}$ [Nimis and Grutter, 2010], but the temperature estimates of approximately $800^{\circ} \mathrm{C}$ beneath Jagersfontein and $900^{\circ} \mathrm{C}$ beneath Gibeon at a depth of approximately $100 \mathrm{~km}$ at the time of eruption of the kimberlites are both reasonable and are unlikely to be in error by more than $50^{\circ} \mathrm{C}$. Importantly, the $100^{\circ} \mathrm{C}$ relative difference between the two is accurate as the same geothermometer was used for all four samples. Recent analyses by Baptiste et al. [2012, Figure 5] of samples from the Kaapvaal craton using different geobarometers and geothermometers fall on a geotherm inferring a temperature at $100 \mathrm{~km}$ in the range $760-780 \pm 60^{\circ} \mathrm{C}$, consistent with the above.

[20] Type I kimberlites of the Kaapvaal Craton and neighboring mobile belts erupted in the period
105-70 Ma during and toward the end of a thermal event thought to have begun with the initiation of Type II kimberlitic volcanism at around 150$115 \mathrm{Ma}$ [Kobussen et al., 2009]. Subsequent thermal relaxation since eruption resulted in colder conditions than those indicated by the xenolith samples, accounting for an estimated cooler present-day temperature of around $740^{\circ} \mathrm{C}$ at $100 \mathrm{~km}$ beneath the Witwatersrand Basin in the center of the Kaapvaal Craton [M. Q. W. Jones, 1988]. The present-day geotherm beneath the Rehoboth Terrane is known to be higher than beneath the Kaapvaal Craton [Muller et al., 2009], consistent with the conditions at kimberlite eruption some 80 Myr ago. Therefore, we adjust the xenolithdetermined temperatures downward by $50^{\circ} \mathrm{C}$ to give estimates of present-day temperatures of $740^{\circ} \mathrm{C}$ and $850^{\circ} \mathrm{C}$ at $100 \mathrm{~km}$ depth beneath Jagersfontein and Gibeon respectively.

[21] A recent estimate for thermal cooling at Gibeon is provided by Schmädicke et al. [2011] of $1,100-1,190^{\circ} \mathrm{C}$ for Type II eclogitic kimberlites cooling to $965-1,000^{\circ} \mathrm{C}$ for the later Type I kimberlites, i.e., approximately $160^{\circ} \mathrm{C}$ of cooling in approximately $60 \mathrm{Myr}$. This is qualitatively consistent with our estimate of $50^{\circ} \mathrm{C}$ of exponentially decaying, temperature-dependent conductive cooling over the last $80 \mathrm{Myr}$ since eruption.

[22] The value for Jagersfontein we adopt is warmer than the recently calculated estimate of $\sim 650$ $695^{\circ} \mathrm{C}$ by Fullea et al. [2011, Figure 12] from their modeling of MT and xenolith data, heat flow and elevation using LitMod [Afonso et al., 2008; Fullea et al., 2009]. (LitMod allows for petrological and geophysical modeling of the lithosphere and sublithospheric upper mantle using as many observables as possible within an internally consistent thermodynamic-geophysical framework.) In contrast, our adopted value for Gibeon is somewhat cooler than the Rehoboth estimate of $\sim 890-985^{\circ} \mathrm{C}$ determined by Fullea et al. [2011]. However, these temperature estimates by Fullea et al. [2011] are 
from the MT data themselves with assumptions about the water model (averaged Poe model used), thus it would be a circular argument to use these thermal estimates in this paper rather than the more conservative values we have adopted based on xenolith observations and thermal relaxation arguments.

[23] Using the compositions defined by the xenoliths and the temperature estimates, we form a modal mineralogical average for each locality from the mineralogy determined in the two individual xenolith samples (Table 3), and use those averages to derive expected values of electrical conductivity for the whole rock.

\subsection{Water Content Estimates}

[24] Water content estimates in olivine from kimberlitic xenoliths from the hundreds of kimberlites penetrating through Kaapvaal Craton have been derived by a number of experimentalists over the last two decades. Rossman [2006] gives a good review of the various experimental procedures, including a historical perspective, and there are recent comparisons of approaches in Thomas et al. [2009] and Mosenfelder et al. [2011]. We adopt herein the Bell calibration and use wt ppm water throughout (abbreviated to $\mathrm{ppm}$ ), and convert where reported otherwise (see Appendix A for discussion).

[25] Water content estimates for olivines from the lithospheric mantle of the Kaapvaal Craton have been presented since the paper of Kurosawa et al. [1997, Table 5]. Those authors reported values of 18-70 wt ppm water (average of $50 \pm 16 \mathrm{wt}$ ppm $\mathrm{H}_{2} \mathrm{O}$ ) for 7 garnet peridotite xenoliths, predominantly from Lesotho, with geobarometric pressures of 39-66 kbar (Köhler and Brey's [1990] geobarometer), approx. 120-200 km depths. Kurosawa et al. [1997] noted in their analyses an increase in water content with pressure, and a decrease with temperature, which is somewhat puzzling as both $\mathrm{P}$ and $\mathrm{T}$ increase with depth. Grant et al. [2007, Table 3] analyzed four garnet peridotite xenoliths from the Kaapvaal Craton and reported water contents of 7.5-54 wt ppm OH (Bell calibration), with more tightly defined Opx and Cpx water contents of $180-200$ and $350-400$ respectively. Geobarometric pressures of 3.77.0 GPa give depths of $110-210 \mathrm{~km}$ for those samples, with the shallowest sample exhibiting the highest water content in olivine and the deepest sample exhibiting the lowest. There were no pressuredependent trends observed in the Opx and Cpx data.

[26] Peslier et al. [2010b] present the results of analyzing 18 carefully selected (see below regarding water loss during ascent) xenolith samples from the Kaapvaal Craton, and present them, together with the data of Kurosawa et al. [1997] and Grant et al. [2007], against pressure, temperature, oxygen fugacity and forsterite content [Peslier et al., 2010b, Figure 1]. The Lesotho kimberlitic samples exhibit consistently lower water contents, by 20-30 ppm, than those from the western Kaapvaal Craton kimberlites; Kimberly, Jagersfontein and Finch. In agreement with Grant et al. [2007], Peslier et al. [2010b] find a pressure-dependency [Peslier et al., $2010 \mathrm{~b}$, Figure 1a], with highest values of water content in olivine some $60-80$ ppm wt $\mathrm{H}_{2} \mathrm{O}$ (Bell calibration) for pressures 3.3-5.5 GPa, approximately $100-165 \mathrm{~km}$ depth. At greater depths the water content decreases systematically to $<10 \mathrm{ppm}$ by $200 \mathrm{~km}$, and there is the inference, from very sparse data, that water content also might decrease at shallower depths. This trend is replicated with temperature, as one would expect, with highest values for temperatures of $900-1200^{\circ} \mathrm{C}$ decreasing systematically with increasing temperature to $<10 \mathrm{ppm}$ by $1350^{\circ} \mathrm{C}$, i.e., the base of the thermal lithospheric mantle. There is also a trend with iron content, with highest water contents for magnesium numbers (Mg\#) of 92.5-94, i.e., depleted rocks, and decreasing with increasing iron to $<40 \mathrm{ppm}$ for $\mathrm{Mg} \#<90$, i.e., more fertile rocks. Thus, there is a two-part division of the lithosphere beneath the western Kaapvaal craton, with the upper lithosphere being more depleted, colder and wetter, and the lower lithosphere being more fertile, warmer and dry.

[27] These results are verified in a very recent paper by Baptiste et al. [2012] that describes measurements of water contents in olivines and pyroxenes for 14 samples equilibrated at different depths from the Kaapvaal Craton. Consistent with prior work, Baptiste et al. [2012] find water contents in olivine are maximum (150 ppm wt $\mathrm{H}_{2} \mathrm{O}$, Bell calibration) for depths of $\sim 160 \mathrm{~km}$, in contrast to those from depths greater than $180 \mathrm{~km}$ that are almost dry. Their single Jagersfontein sample (KBJ59) yielded a geothermometric temperature of $890^{\circ} \mathrm{C}$ [Brey and Köhler, 1990], which is some $100^{\circ} \mathrm{C}$ higher than our temperature estimate for $100 \mathrm{~km}$ depth and would suggest a somewhat deeper source region. There is no geobarometric depth estimate for that sample, but comparison with the derived geotherm in Baptiste et al. [2012, Figure 5] would suggest that the sample came from $\sim 115 \mathrm{~km}$ depth. The five olivines from sample KBJ59 yielded a range of water contents of 66-202, with an average of $110 \pm 55$ ppm wt $\mathrm{H}_{2} \mathrm{O}$ (Bell calibration), which is 
somewhat higher than the Peslier et al. [2010b] estimates. Their coldest Kimberley sample (FRB1423, $851^{\circ} \mathrm{C}$, Brey and Köhler geothermometer) yielded two water content estimates of 63 and $133 \mathrm{ppm}$, within the range of the Jagersfontein sample.

[28] Taking all of these values together, for a depth of $100 \mathrm{~km}$ below Jagersfontein we conclude that an

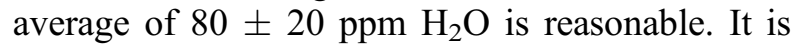
certainly not higher than about $150 \mathrm{ppm}$, nor lower than about $60 \mathrm{ppm}$.

[29] The petrological observation by Peslier et al. [2010b] and Baptiste et al. [2012] that the uppermost depleted lithospheric mantle is wetter than the lowermost melt-metasomatized and re-fertilized mantle was a conclusion drawn from modeling the magnetotelluric data on the Kaapvaal Craton together with surface elevation and heat flow by Fullea et al. [2011] using the LitMod approach [Afonso et al., 2008; Fullea et al., 2009].

[30] We assume that the water content in the olivine from the Rehoboth Terrane at $100 \mathrm{~km}$ is also of the order of $80 \mathrm{ppm}$, with the pyroxenes two times and three times higher for Opx and Cpx respectively. Off-craton peridotites are, puzzlingly, typically lower in their water contents in olivine, with water in Ol usually $<50 \mathrm{ppm}$, but are the same in pyroxenes, with averages of $163 \mathrm{ppm}$ in Opx and 307 in Cpx [Peslier, 2010]. For our purposes we adopt a value of $80 \mathrm{ppm}$ for Gibeon also, and err on the conservative side.

\subsection{Water Loss During Ascent}

[31] The issue of potential water loss during kimberlitic magmatic ascent is clearly one that can play a major role in the veracity of our examination, and has been a concern for two decades [Mackwell and Kohlstedt, 1990]. Petrological evidence exists, namely the differential water content seen from rims to cores of the mantle grains, that yields strong support for potentially significant water loss in olivine in alkali basalts during ascent [Demouchy et al., 2006]; Demouchy et al. [2006] consider up to two thirds of the water in olivine may be lost. For kimberlitic xenolithic olivines, the amount of water lost from olivine appears to depend on the host magma, and, generally, the $\mathrm{H}^{+}$diffusion profiles are far less pronounced than for alkali basalts. This difference is ascribed to kimberlitic magmas being more volatile rich, at lower temperatures (1000-1200 ${ }^{\circ} \mathrm{C}$, compared to $\sim 1200-1300^{\circ} \mathrm{C}$ ) and with far higher ascent rates (up to $37 \mathrm{~m} / \mathrm{s}$, compared to $6 \mathrm{~m} / \mathrm{s}$ ) than alkali basalts [Peslier et al., 2008].
Peslier [2010], in her review on water in the Earth's mantle, gives only two localities for which one can be fairly certain that water loss did not occur in olivine from alkali basalts during ascent, namely Kilbourne Hole (New Mexico, USA) and Ichinomegata (Japan); Kilbourne Hole has low values of water in olivine, 3-54 ppm [Grant et al., 2007]. In contrast, many olivines in xenoliths from kimberlitic magmas exhibit flat hydrogen profiles and can reasonably be assumed to be representative of the water content in olivine at source [Peslier, 2010]. Consistent with the prior results of Grant et al. [2007], Peslier et al. [2008] found no hydrogen profile variation across olivine grains from the Kaapvaal craton, with the exception of one anomalous sample.

[32] In the case of the water content values used in this paper, taken from Peslier et al. [2010b, p. 78], those authors stated that "Diffusion modelling of the $\mathrm{H}$ profiles across the olivine of these samples (Supplementary Information) reveals that the cores of the olivine preserved their original water content and that only the edges were affected by $\mathrm{H}$ loss. Consequently, the water contents presented here are believed to reflect accurately the mantle values." We therefore assume that the water contents reported by Peslier et al. [2010b], and recently by Baptiste et al. [2012], for the Jagersfontein xenoliths of around $80 \mathrm{ppm}$, are representative to within $\pm 20 \mathrm{ppm}$. It is highly unlikely that the actual water content is more than two times greater, i.e., $>160 \mathrm{ppm}$, as could be argued for olivines from alkali basalts.

[33] We cannot though exclude the possibility that, despite the observations of flat hydrogen profiles in the olivine grains from kimberlitic xenoliths, the water contents in olivines have all been systematically underestimated. That alternative, unlikely though it is, is explored in the Discussion and Conclusions.

[34] Hydrogen diffusion profiles of pyroxenes and garnet indicate that they do not appear to lose any water during ascent, but why there is this difference between water loss in olivine compared to the other minerals is the subject of speculation [see Peslier, 2010, and references therein].

\subsection{Water Partitioning}

[35] We have two regions where we can define the observed electrical resistivity and where we know modal mineralogy and can estimate present-day temperature reasonably well. For Jagersfontein, we also have an estimate of the water content in olivine, but for our calculations we need to assume the water 
partitioning in the pyroxenes. Water partitioning in NAMs was discussed by Aubaud et al. [2004, 2007], Hauri et al. [2006], and Li et al. [2008], among many others, and the inconsistency between various studies is beyond the scope of this paper. We require only an approximate rule for our calculations.

[36] Typically there is up to twice as much water in Cpx as Opx [Li et al., 2008; Peslier, 2010], but, given the small amounts of Cpx in our samples $(<5 \%)$, the effect of water variation in Cpx on bulk conductivity is negligible. Global cratonic averages give water contents in cratonic peroditic xenoliths of $58 \mathrm{ppm}$ in Olivine, $157 \mathrm{ppm}$ in Opx, and $276 \mathrm{ppm}$ in Cpx [Peslier, 2010] - a ratio of 1:2.7:4.7 - with whole rock water content of $58 \mathrm{ppm}$ (same as olivine). Averages for water in South African cratonic pyroxenes are $244 \pm 107 \mathrm{ppm}$ for Opx and $397 \pm 61 \mathrm{ppm}$ for Cpx, with a whole rock average of $124 \pm 62$ ppm [Xia et al., 2010]. If the whole rock sample is reasonably representative of the olivine water content this supports an approximately 1:2:3 partitioning, which is close to the partitioning seen at Monastery kimberlite in Lesotho by Bell et al. [2004] of 1:1.6 $( \pm 0.2): 3.0( \pm 0.5)$.

[37] We recognize in global compilations that whereas the partitioning between Opx and Cpx is reasonably supported by observation [Peslier, 2010, Figure 2a], there is less support for a partitioning relationship between Ol and Opx [Peslier, 2010, Figure 2d], and indeed one could argue from global extant data that $\mathrm{Ol}$ water content varies independently of Opx water content. However, the error introduced by adopting an incorrect partitioning relationship is minor compared to all of the other variables and unknowns, and we thus assume for our calculations that there is twice as much water in Opx as in Ol, and three times as much in Cpx. To the best of our knowledge there are no laboratory measurements at lithospheric-mantle temperatures and pressures that constrain the equilibrium partitioning of water between Ol, Opx and Cpx. Therefore, recourse to the observed relative water concentrations in xenolith samples, as has been done here, is the only possible approach for estimating water partitioning between the three major mantle minerals.

\section{Petrologically Defined Electrical Conductivity of Mantle Rocks}

\subsection{Electrical Conductivity of Mantle Minerals}

[38] For electrical conductivity the equations of state for dry mantle minerals are reviewed in detail in Jones et al. [2009a], and, for small polaron conduction, are given as

$$
\begin{aligned}
\sigma_{\mathrm{Ol}} & =\left(\frac{10^{6.54}}{\mathrm{~T}}\right) \mathrm{X}_{\mathrm{Fe}}^{1.81} e^{-1.35(\mathrm{eV}) / \mathrm{kT}}, \\
\sigma_{\mathrm{Opx}} & =10^{3.72} e^{-1.80(\mathrm{eV}) / \mathrm{kT}}, \\
\sigma_{\mathrm{Cpx}} & =10^{3.25} e^{-1.87(\mathrm{eV}) / \mathrm{kT}}, \quad \text { and }, \\
\sigma_{\mathrm{Gt}} & =10^{\left(4.26-12.26 \mathrm{X}_{\mathrm{Fe}}\right)} e^{-\left(2.40-6.0 \mathrm{X}_{\mathrm{Fe}}\right)(\mathrm{eV}) / \mathrm{kT}},
\end{aligned}
$$

based on the work of Hirsch et al. [1993] for Ol, $X u$ and Shankland [1999] for Opx, Xu et al. [2000] for Cpx, and Romano et al. [2006] for Gt (but with a correction applied, see Jones et al. [2009a]), where mineral $\mathrm{X}_{\mathrm{Fe}}$ is the iron number (related to the magnesium number $\mathrm{Mg} \#$ by $\mathrm{X}_{\mathrm{Fe}}=1-\mathrm{Mg} \# / 100$; can be different for each mineral), $\mathrm{k}$ is Boltzmann's constant, and $\mathrm{T}$ is temperature in Kelvin. Note that the conductivities of the pyroxenes are not irondependent - this is because either the measurements have not been made or the laboratories are inconsistent in their results (see discussion in Jones et al. [2009a]), so we have little choice but to assume iron dependency is negligible. Also, spinel is ignored as the evidence from mantle xenoliths is that its occurrence is well below $1 \%$ at the depth of interest in this paper $(100 \mathrm{~km})$.

[39] Fullea et al. [2011] revised the above equations taking into account newer laboratory studies and also the measurements of the effects of water in the minerals. The revised equations are of the general form

$$
\sigma=\sigma_{0, s p} \exp \left(\frac{-\Delta H\left(\mathrm{X}_{\mathrm{Fe}}, P\right)}{k T}\right)+\sigma_{0 i} \exp \left(\frac{-\Delta H_{i}}{k T}\right)+\sigma_{\mathrm{p}}
$$

where

$$
\begin{aligned}
& \Delta H\left(\mathrm{X}_{\mathrm{Fe}}, P\right)=a+b \mathrm{X}_{\mathrm{Fe}}+c \mathrm{X}_{\mathrm{Fe}}^{2}+d \mathrm{X}_{\mathrm{Fe}}^{3}+e \mathrm{X}_{\mathrm{Fe}}^{4}+f \mathrm{X}_{\mathrm{Fe}}^{5}+P \Delta V \\
& \text { and } \sigma_{\mathrm{p}}=f\left(C_{w}\right) \exp \left(\frac{-\Delta H_{w e t}\left(C_{W}\right)}{k T}\right) .
\end{aligned}
$$

The first term in equation (10) describes small polaron conduction, and includes a dependency on mineral iron number $\mathrm{X}_{\mathrm{Fe}}$. The second term describes the contribution of $\mathrm{Mg}$ vacancies at high temperatures (and lacks $\mathrm{X}_{\mathrm{Fe}}$ dependency). The third term describes proton conduction in the water-present case, as described in the general case by equation (1).

[40] At the conditions of interest in this study, the temperatures are sufficiently low that conduction from $\mathrm{Mg}$ vacancies is negligible (it only becomes important at temperatures beyond $1200^{\circ} \mathrm{C}$ ). 


\subsection{Variation of Olivine Conductivity With Temperature}

[41] The small polaron conductivity models of olivine at cratonic lithosphere temperatures, for a representative magnesium number for cratonic lithosphere $(\mathrm{Mg} \#=92.5)$ and typical pressure at $100 \mathrm{~km}$ depth (3.25 GPa), from Jones et al. [2009a] (equation (9)) and Fullea et al. [2011] (equations (10) and (11) with the parameters from Table 4) are shown in Figure 4, together with the SEO3 defined conductivity of Constable [2006] at both QFM and IW oxygen buffering conditions.

[42] Also shown in Figure 4 are the conductivity estimates for proton conduction for $100 \mathrm{ppm}$ water from the three models, Karato (Figure 4, dashed black line), Yoshino (Figure 4, dashed red line) and Poe (Figure 4, dashed blue line). Comparing Figure 1 with Figure 4, proton conduction dominates over small polaron conduction for even small amount of water; $<45 \mathrm{ppm}$ for the Poe AV model and far less for the other two models. Thus, the differences between the polaron models and the errors introduced by adopting a particular polaron conductivity model, and also ignoring iron effects on pyroxene conductivity, are irrelevant at the water contents of interest in this study given the dominance of proton conduction.

[43] Note that for the water contents of interest, the proton conduction term has a relatively small gradient with temperature, regardless of model chosen, of approx. 0.37-0.42 log units for a $100^{\circ} \mathrm{C}$ change. Thus, a $50^{\circ} \mathrm{C}$ error in our present-day temperature estimates for either Jagersfontein $\left(740^{\circ} \mathrm{C}\right)$ or Gibeon $\left(850^{\circ} \mathrm{C}\right)$ will result in an error of $0.2 \log$ units in our estimate of conductivity. This is the same order as the experimental errors of our resistivity estimates (0.20 log units for Jagersfontein and $0.09 \log$ units for Gibeon, see below).

[44] The complete conductivity calculations in temperature-water content $\left(T-C_{w}\right)$ space for the three proton conduction models are shown in Figure 5. For all of them, at low water contents temperature is virtually immaterial. This changes at high water contents, where there is a strong gradient with both temperature and water content for the Poe model, but for the Karato and Yoshino models conductivity becomes insensitive to actual water content, as discussed above. 
Polaron and proton olivine conductivity

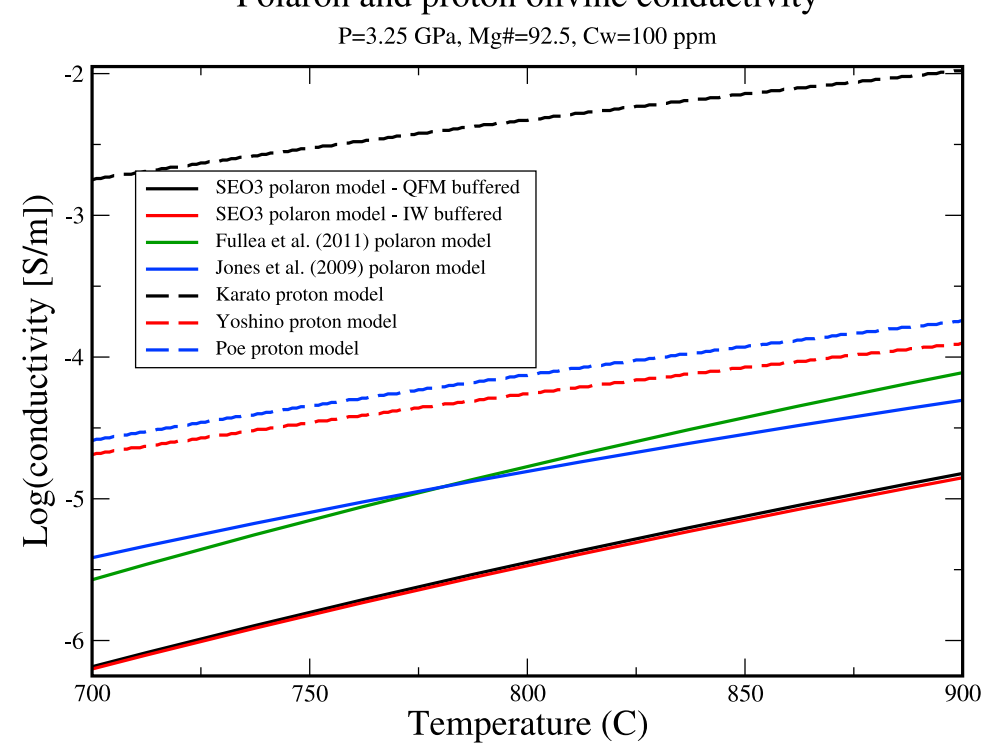

Figure 4. Variation of conductivity with temperature for olivine at a pressure of $3.25 \mathrm{GPa}(\sim 100 \mathrm{~km}$ depth$)$ with an $\mathrm{Mg \#}$ of 92.5 and a water content of $100 \mathrm{ppm}$. Small polaron conductivity from the Fullea et al. [2011] (green solid line) and Jones et al. [2009a] (blue solid line) models plus the SEO3 model of Constable [2006] for both QFM (black solid line) and IW (red solid line) oxygen fugacity buffering. Proton conductivity from the Karato (dashed black line), Yoshino (dashed red line) and Poe (dashed blue line) models.

\subsection{Whole Rock Conductivity Calculation}

[45] The parameters used for equations (10) and (11) for the four minerals are listed in Table 4. In implementing the generalized form for proton conduction, $\sigma_{p}$, in equation (11) for the different conduction models derived by the three laboratories, the following formulations were used (with parameters specified in Table 3): (1) For the Karato model, a constant value of $\Delta H_{\text {wet }}$ (i.e., $\alpha$ assumed to be zero) and $f\left(C_{w}\right)=\sigma_{0} C_{w}^{r}$. (2) For the Yoshino and Poe models, $\Delta H_{\text {wet }}=\Delta H_{0}-\alpha C_{w}^{(1 / 3)}$ and $f\left(C_{w}\right)=\sigma_{0} C_{w}$ (i.e., $r$ assumed to be one).

[46] Following the Jones et al. [2009a] approach, we calculate whole rock conductivity for the four samples and two averages using the $(\mathrm{P}, \mathrm{T})$ conditions and modal compositions from Table 3, the formulae in equations (10) and (11), and aggregate the individual minerals using second-order, multiphase Hashin-Shtrikman extremal bounds [Berryman, 1995], taking into account possible interfacial effects [Salje, 2007]. Simple mixing laws, such as arithmetic or geometric relations, Archie's Law, and Voigt and Reuss estimates, give first-order variational bounds, whereas Hashin-Shtrikman represents a member of the class of second-order variational bounds. There exist third-order variational bounds [Beran, 1965; Beran and Molyneux, 1966] that have been applied in seismology $[X F X u, 2011]$ but not yet in electromagnetism. An additional term was added to the Hashin-Shtrikman equations of Berryman [1995] by Salje [2007] to explain observations that were found to lie outside the HashinShtrikman bounds. The term considers interfacial effects that are shown to scale with $f(1-f)$, where $f$ is the volume proportion of the individual phase. For intermediate cases, where both volume and interfacial effects are important, the volume proportion $f$ in the averaging scheme is replaced by $f(1-S)+S f^{2}$, where $S$ ranges from 0 (no interfacial effects) to 1 (only interfacial effects).

[47] Extremal bounds are more important for electrical conductivity than for bulk moduli, as the influence of the highest conductivity phase, even if only a minor component $(1 \%)$, can be dramatic if the minor phase is sufficiently well interconnected. However, olivine $(\mathrm{Ol})$ and pyroxene $(\mathrm{Opx}, \mathrm{Cpx})$ minerals when dry have conductivities that are within an order of magnitude of each other at any given $(\mathrm{P}, \mathrm{T})$ conditions, and, for the mineral assemblages considered herein, $\mathrm{Ol}$ and Opx make up the bulk of the whole rock, over 95\% in most cases, so the extremal bounds are not wide. We derive estimates using the geometric means of the upper and lower Hashin-Shtrikman bounds with and without interfacial effects; the individual values are so close to each other that the geometric and arithmetic means are virtually the same. 


\section{a}

\section{Karato proton model conductivity}

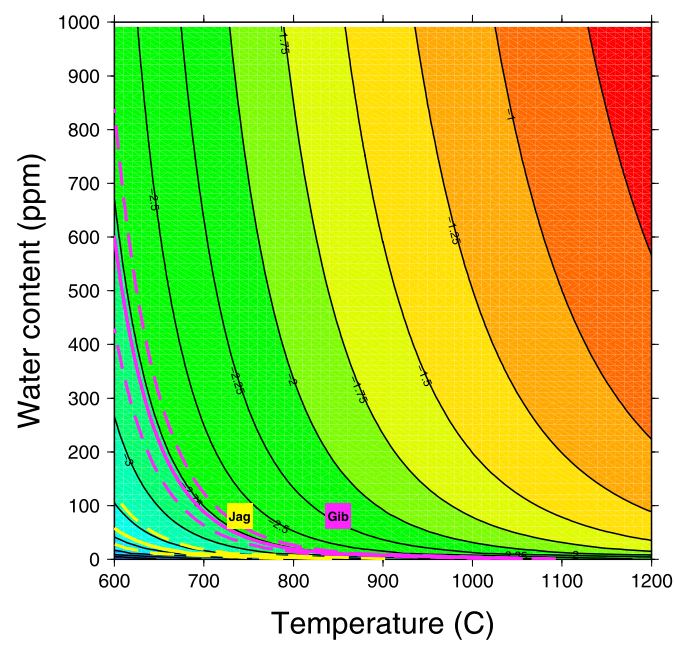

\section{C}

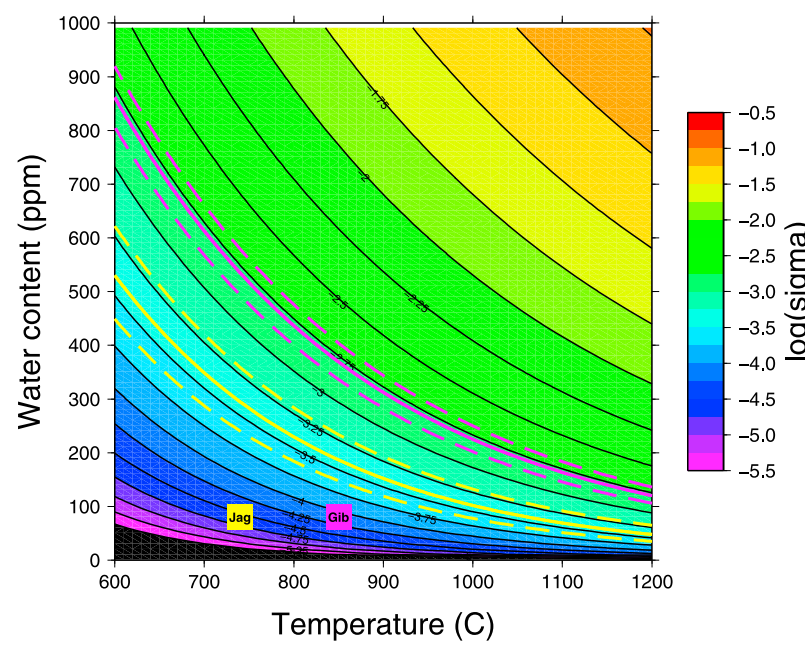

\section{b Yoshino proton model conductivity}

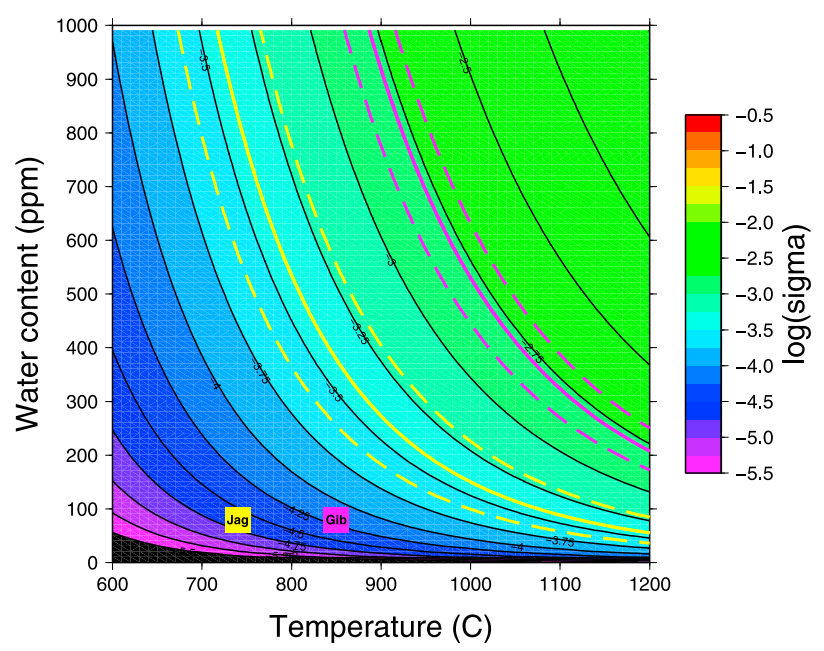

d This paper proton model conductivity

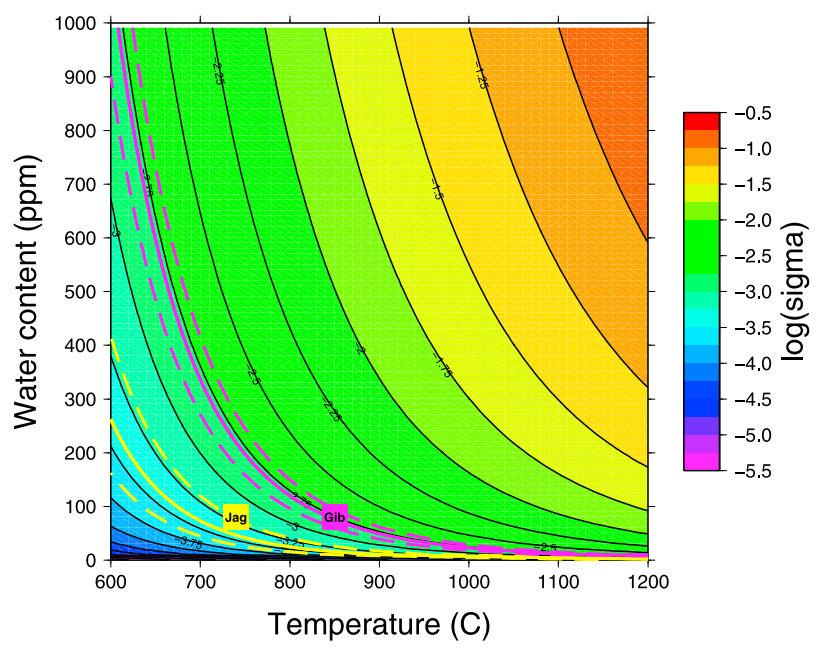

Figure 5. Electrical conductivity from proton conduction with temperature and water content using equation (1) with the parameters listed in Table 1 for (a) the Karato [Wang et al., 2006], (b) the Yoshino [Yoshino et al., 2009], (c) the averaged Poe [Poe et al., 2010; Fullea et al., 2011], and (d) this paper's model parameters. Also shown are the expected temperatures and water contents for Jagersfontein (Jag, $740^{\circ} \mathrm{C}, 80 \mathrm{ppm}$, yellow square) and Gibeon (Gib, $750^{\circ} \mathrm{C}, 80 \mathrm{ppm}$, purple square), and the resistivities at $100 \mathrm{~km}$ depth below Jagersfontein $(-3.41 \pm 0.2 \log$ units, solid yellow line with one sigma errors shown as dashed yellow lines) and Gibeon $(-2.78 \pm 0.09$ log units, solid purple line with one sigma errors shown as dashed purple lines).

[48] Our average petrologically based estimates for $\log _{10}$ (conductivity) at $100 \mathrm{~km}$ depth beneath Jagersfontein and Gibeon, under water-absent, dry conditions, i.e., small polaron conduction only, are -5.30 and $-4.39 \log$ units respectively (Table 5).

[49] Given the observations of water in the lithosphere, we must derive the expected conductivities under "slightly damp," conditions. None of the data in Peslier et al. [2010b] are from xenoliths sourced as shallow as $100 \mathrm{~km}$ nor as cold as $740^{\circ} \mathrm{C}$, so we have to extrapolate from their results at higher temperatures $\left(900^{\circ} \mathrm{C}\right)$ beneath Kimberley that show evidence for around $80 \mathrm{ppm}$ water in the olivine. Given the lack of any depth-dependence shown for the upper lithosphere in Peslier et al. [2010b], we assume a value of $80 \pm 10 \mathrm{ppm}$ later in the text, but calculate at this point conductivity for water content from 0-200 ppm in olivine. 
Table 5. Hashin-Shrikman Estimates of $\log _{10}$ (Conductivity $[\mathrm{S} / \mathrm{m}]$ ) at $100 \mathrm{~km}$ Depth Beneath Jagersfontein (FRB Samples) and Gibeon (KGG Samples), Assuming Dry Conditions (No Water) ${ }^{\mathrm{a}}$

\begin{tabular}{lcccccc}
\hline \multicolumn{1}{c}{ Sample } & $\begin{array}{c}\mathrm{T} \\
\left({ }^{\circ} \mathrm{C}\right)\end{array}$ & $\begin{array}{c}\mathrm{HS}^{-} \\
(\mathrm{S}=0)\end{array}$ & $\begin{array}{c}\mathrm{HS}^{+} \\
(\mathrm{S}=0)\end{array}$ & $\begin{array}{c}\mathrm{HS}^{-} \\
(\mathrm{S}=1)\end{array}$ & $\begin{array}{c}\mathrm{HS}^{+} \\
(\mathrm{S}=1)\end{array}$ & $\begin{array}{c}\mathrm{HS} \\
\mathrm{GAV}\end{array}$ \\
\hline FRB983 & 710 & -5.53 & -5.20 & -5.49 & -5.49 & -5.43 \\
FRB1007 & 755 & -5.18 & -4.76 & -5.19 & -5.16 & -5.07 \\
FRB AV & 740 & -5.30 & -4.96 & -5.29 & -5.28 & $-\mathbf{5 . 2 1}$ \\
KGG06 & 875 & -4.34 & -3.86 & -4.36 & -4.24 & -4.20 \\
KGG65 & 825 & -4.68 & -4.12 & -4.71 & -4.59 & -4.52 \\
KGG AV & 850 & -4.51 & -3.99 & -4.53 & -4.41 & $-\mathbf{4 . 3 6}$ \\
\hline
\end{tabular}

${ }^{a}$ The parameter $\mathrm{S}$, varying between 0 and 1 , accounts for the potential variation in the strength of interfacial processes on conductivity. HS GAV refers to the geometric average of the Hashin-Shtrikman estimates. Temperatures used are estimated present-day temperatures and are approximately $50^{\circ} \mathrm{C}$ less than temperatures at the time of kimberlite eruption (Table 3). Bold values represent the averages that are used in this paper.

[50] The conductivity calculations for wet conditions for olivine for the Karato, Yoshino and Poe (average) models that include the effects of proton conduction using equations (10) and (11) for temperatures of $740^{\circ} \mathrm{C}$ and $850^{\circ} \mathrm{C}$, i.e., our Jagersfontein and Gibeon estimated ambient temperatures at $100 \mathrm{~km}$, are shown as the dashed lines in Figure 6.

[51] Olivine is not the only mantle mineral, even though it comprises $>70 \%$ (Table 3 ) of the rock mass, so consideration must be given to the contribution to proton conduction from the other mantle minerals, pyroxenes and garnet, of which Opx dominates. Water in pyroxenes is higher than in olivine, with averages of $200 \mathrm{ppm}$ in Opx and $300 \mathrm{ppm}$ in Cpx, and virtually zero in garnet, in the Kaapvaal peridotite xenolith samples reported in Peslier [2010, supplementary material]. A recent abstract lists a narrow range for both Opx and Cpx of 119-251 ppm and 149-398 ppm respectively [Peslier et al., 2010a], bracketing the average given above, with the intriguing suggestion of an increase in water content in pyroxenes from Liqhobong (Lesotho), through Finsch Mine, Jagersfontein, to Kimberley xenoliths. In contrast, far lower values are reported for xenoliths from the Letseng kimberlite in Lesotho [Sundvall and Stalder, 2011], from $20 \mathrm{ppm}$. As discussed above, we assume a water partitioning of 1:2:3 between the Ol, Opx and Cpx.

[52] Computing the resistivities for the composition given in Table 3 for water contents of $x \mathrm{ppm}$ in Ol, 2x ppm in Opx, 3x ppm in Cpx, and 0 ppm in Gt (values observed are $0-15 \mathrm{ppm}$ at $4 \mathrm{Gpa}$ in Peslier [2010], but given the very low volumes of these minerals we set the water contents to zero), where $x$ varies from 0 to 200 and the increase in water in pyroxenes is assumed to be linearly related to the increase in water in olivine, yields the solid lines shown in Figure 6 a for the conductivity beneath Jagersfontein with varying water content. Holding the water contents of the pyroxenes fixed at the averages of $200 \mathrm{ppm}$ and $300 \mathrm{ppm}$ for Opx and Cpx respectively and varying $\mathrm{Ol}$ only from 0 to $200 \mathrm{ppm}$ introduces very little change in our conductivity estimates over assuming a 1:2:3 water partitioning, especially at the water contents of interest, around 80 ppm.

[53] The water content of minerals from xenoliths beneath Gibeon is unknown, but it is reasonable to assume that it will be of the same order, if not somewhat less. Undertaking the computations for Gibeon parameters (Table 3) yields the solid lines in Figure $6 \mathrm{~b}$ for the Karato, Yoshino and Poe models.

\section{Field Observations of Electrical Resistivity at $100 \mathrm{~km}$ Beneath Jagersfontein and Gibeon}

[54] A regional-scale magnetotelluric survey of Southern Africa took place during 2003-2008 called SAMTEX (Southern African MT Experiment) [Jones et al., 2009b], following on from the teleseismic SASE (Southern African Seismic Experiment) [James et al., 2001] project. Two-dimensional resistivity models have been published from three of the main profiles, a SW-NE profile across the Kaapvaal Craton [Evans et al., 2011], a crossing NW-SE profile from the Kaapvaal Craton onto the Rehoboth Terrane [Muller et al., 2009], and a N-S profile across the Zimbabwe Craton in northeastern Botswana [Miensopust et al., 2011]. In addition, maps of approximate resistivity at depths of $100 \mathrm{~km}$ and $200 \mathrm{~km}$ from the whole SAMTEX database have been published [Jones et al., 2009b].

[55] The $\log _{10}$ (conductivities) at $100 \mathrm{~km}$ beneath Jagersfontein and Gibeon are estimated by averaging the approximate resistivities in the $100 \mathrm{~km}$ depth image of Jones et al. [2009b]. The means and one-sigma $(1 \sigma)$ bounds within $100 \mathrm{~km}$ radius of the two kimberlite fields are $-3.41 \pm 0.20$ and $-2.78 \pm$ $0.09 \log$ units respectively. These values are substantiated below by undertaking modeling of the sites closest to the two kimberlite fields, and from comparing them with an existing regional twodimensional model. 
Jagersfontein: Comparison of $\mathrm{H} 2 \mathrm{O}$ models

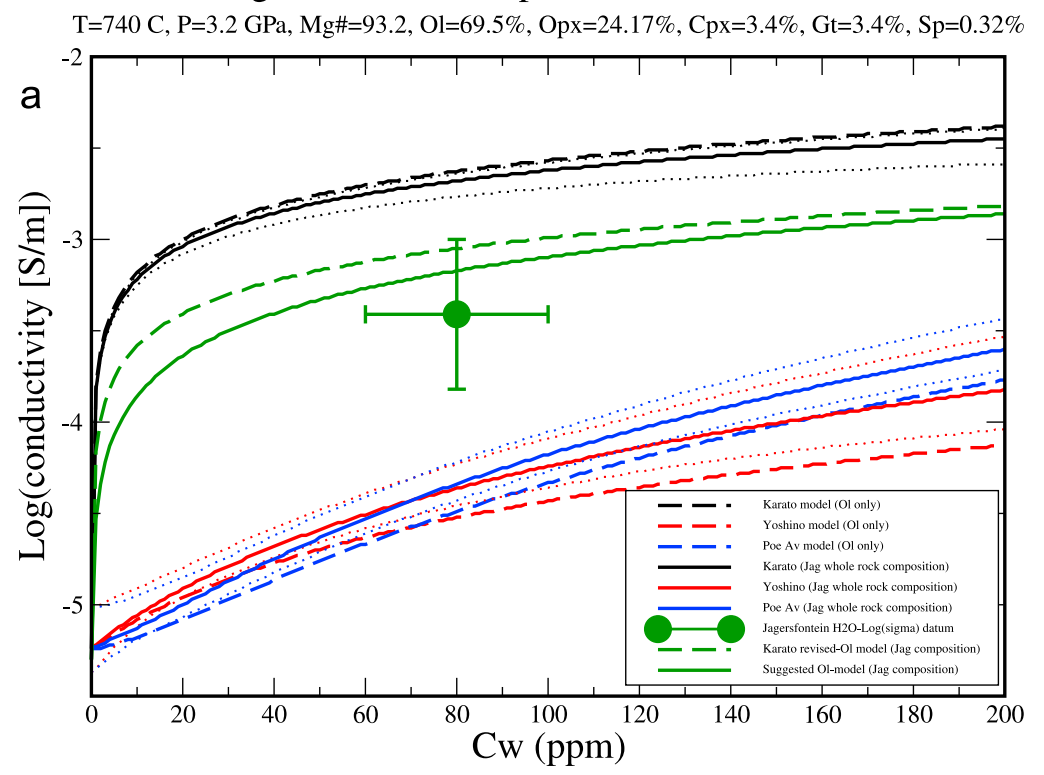

Gibeon: Comparison of $\mathrm{H} 2 \mathrm{O}$ models

$\mathrm{T}=850 \mathrm{C}, \mathrm{P}=3.335 \mathrm{GPa}, \mathrm{Mg} \#=91.8(\mathrm{Gt}=75), \mathrm{Ol}=74.5 \%, \mathrm{Opx}=11.5 \%, \mathrm{Cpx}=6.5 \%, \mathrm{Gt}=7.5 \%, \mathrm{Sp}=0.0 \%$

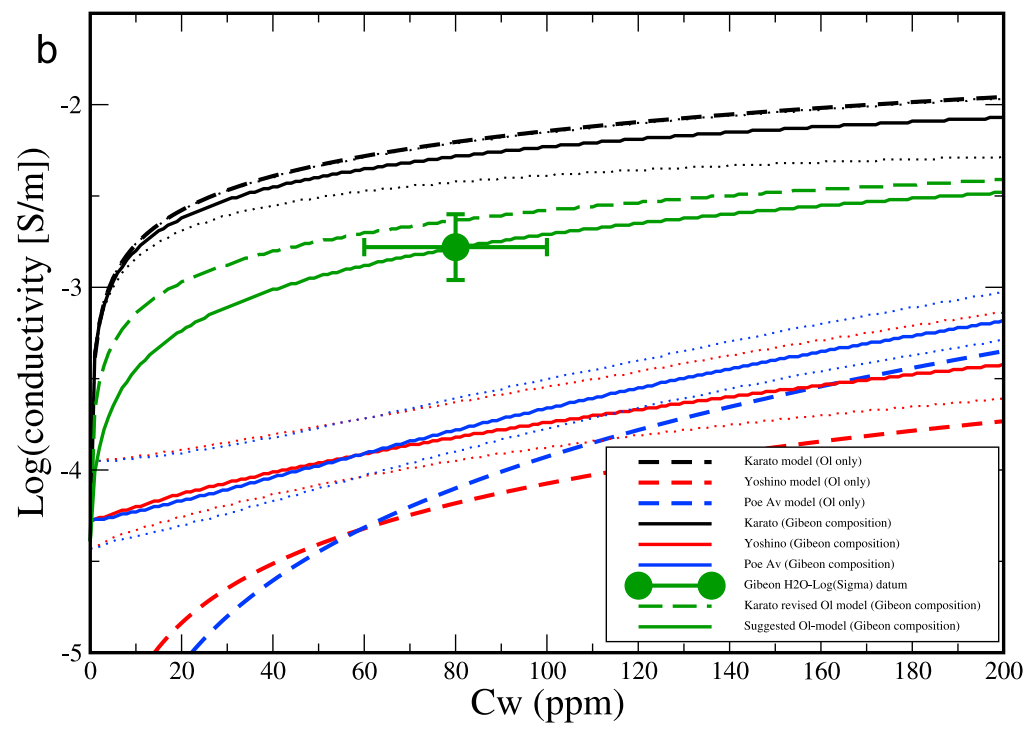

Figure 6. (a) Variation of conductivity at Jagersfontein parameters at $100 \mathrm{~km}$ depth of $\mathrm{T}=740^{\circ} \mathrm{C}, \mathrm{P}=3.2 \mathrm{GPa}$, for olivine water concentration varying from $0-200 \mathrm{ppm}$ for the Karato (black lines), Yoshino (red lines) and Poe (blue lines) models (equation (10)) for olivine alone $(\mathrm{Mg} \#=93.2)$ (dashed lines) and for the Jagersfontein composition assemblage $(\mathrm{Mg} \#=93.2$, except for Gt where $\mathrm{Mg} \#=75.0)$ (solid lines). Note that the abscissa annotates olivine water concentration, and that for the composition assemblage calculations, water concentrations for Opx, Cpx and Gt are taken as $2 \times \mathrm{Ol}, 3 \times \mathrm{Ol}$ and zero respectively, as discussed in the text. The observation datum (green point) is for a water content in $\mathrm{Ol}$ of $80 \pm 20 \mathrm{ppm}$ (from xenoliths) and a $\log$ (conductivity) of $-3.41 \pm 0.41$ (from mapping of MT observations, with $2 \sigma$ error bounds). The dashed green line represent the revised Karato water model for olivine, with $\log \left(\sigma_{0}\right)=2.70( \pm 0.26), r=0.70( \pm 0.12)$, and $\Delta H_{\text {wet }}=0.91( \pm 0.04)$. The solid green line represents the revised water model for olivine that best fits equation (1) with $\log _{10}\left(\sigma_{0}\right)=3.05( \pm 0.16), r=0.86( \pm 0.08), \Delta H_{\text {wet }}=0.91$ ( \pm 0.04$)$, and $\alpha=0.09( \pm 0.07)$, valid for water content in damp lithosphere of around 60-100 ppm. The dotted lines are $\pm 1 \sigma$. (b) Variation of conductivity at Gibeon parameters at $100 \mathrm{~km}$ depth of $\mathrm{T}=850^{\circ} \mathrm{C}, \mathrm{P}=3.335 \mathrm{GPa}$, for water varying from $0-200 \mathrm{ppm}$. The observation datum (green point) is for a water content in $\mathrm{Ol}$ of $80 \pm 20 \mathrm{ppm}$ (assumed to be the same as for Jagersfontein in the absence of xenolith water content measurements at Gibeon) and a $\log$ (conductivity) of $-2.78 \pm 0.18$ (from mapping of MT observations, with $2 \sigma$ error bounds). Curves as for Figure 6a. The dotted lines are $\pm 1 \sigma$. 

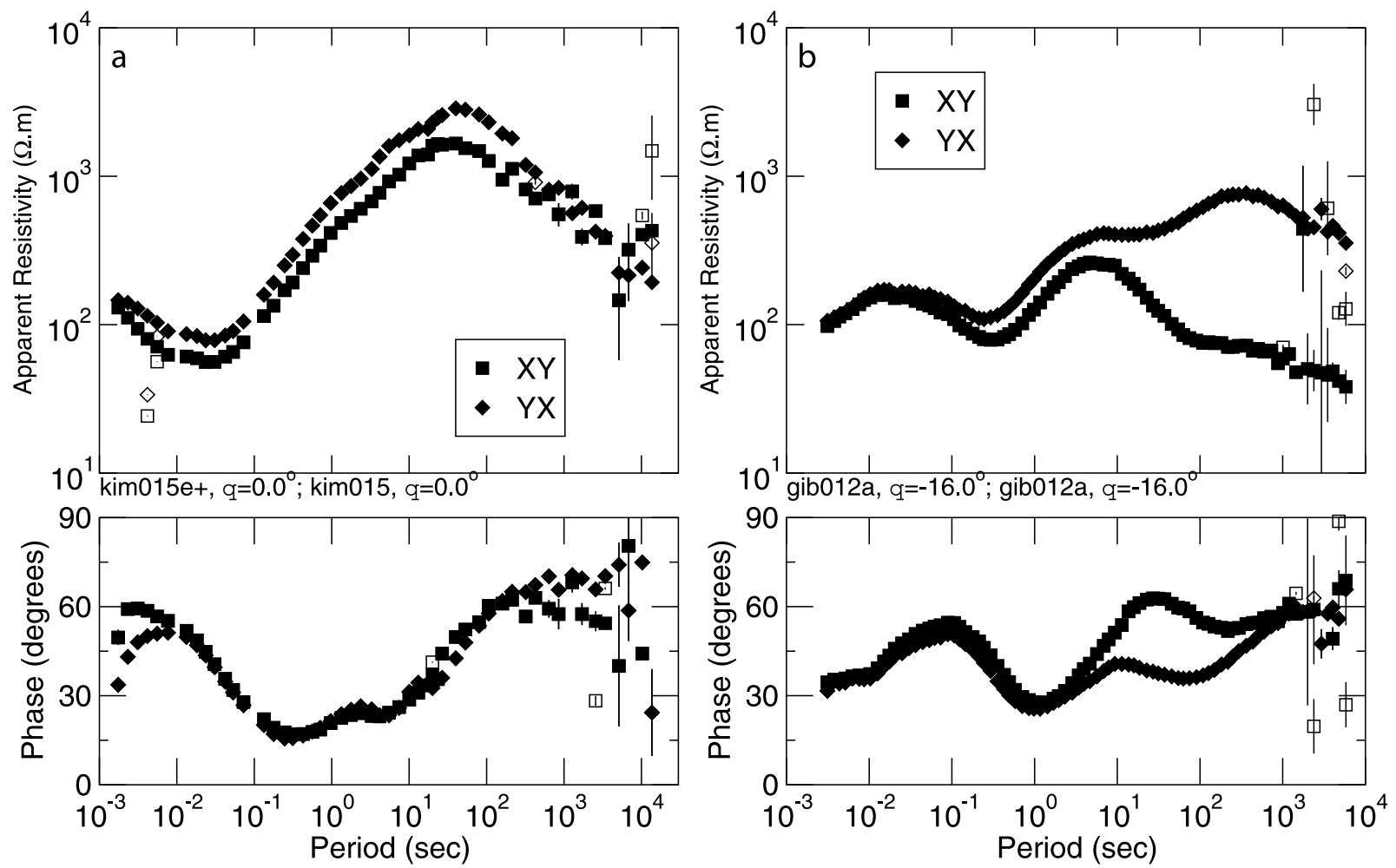

Figure 7. (a) Magnetotelluric data observed at site kim015 within $20 \mathrm{~km}$ of the Jagersfontein kimberlite field. The open symbols are the original estimates of the MT impedance tensor off-diagonal elements (XY and YX, where the YX phases have been rotated from the 3rd into the 1st quadrant), which are a merge of broadband (Phoenix Geophysics MTU-V5) and long period (LIMS) data. The solid symbols are the data after replacing estimates that lie more than $2 \sigma$ away from their Rho+ [Parker and Booker, 1996] estimates. (b) Magnetotelluric data (Phoenix Geophysics MTU-V5 only) observed at site gib012 located within the Gibeon kimberlite field. (Symbols same as in Figure 7a.)

[56] For Jagersfontein, the closest site to the kimberlite field is kim015, and the MT data at this location (Figure 7a) are clearly one-dimensional (1D), with minor static shifts [A. G. Jones, 1988], over the whole period range except for the very longest periods. For Gibeon, the closest site is gib012, and the data (Figure 7b) are 1D at high frequencies, but become 2D at longer periods, with geoelectrical strike close to geographic coordinates.

[57] One-dimensional (1D) models of the Berdichevsky-averaged MT data (i.e., Zav $=Z x y-$ $Z y x)$ from kim015 and gib012, were derived using the Occam approach [Constable et al., 1987] (Figure 8). Minimum possible $\chi^{2}$ misfits are given by the $D+$ solutions of Parker [1980], and for the kim015 and gib012 Zav data are 85.0 and 87.7 respectively, which, for 52 and 84 complex data, are minimum RMS misfits of 0.90 and 0.72 . Two models are shown for each site, one that exhibits the initiation of oscillatory behavior seen when Occam models are pushed too close toward the $D+$ minimum misfit limit, and a second that is some $7-9 \%$ higher misfit that does not show the strong oscillations. Both models at each site are very similar at $100 \mathrm{~km}$ depth and are in agreement with the electrical resistivity at $100 \mathrm{~km}$ depth being around $2,000 \Omega \mathrm{m}$ (i.e., $\log _{10}$ (conductivity) of $-3.30 \log$ units) for Jagersfontein and around $450 \Omega \mathrm{m}\left(\log _{10}\right.$ (conductivity) of $-2.65 \mathrm{log}$ units) for Gibeon.

[58] Two-dimensional (2D) modeling of the SAMTEX profile that traverses SE-NW across Jagersfontein from the Kaapvaal Craton onto the Rehoboth Terrane [Muller et al., 2009] yields conductivity estimates that overlap in error with the above values, but that are somewhat lower. For both Jagersfontein and the Gibeon field, $\log _{10}$ (resistivity) averages of the $2 \mathrm{D}$ model at $100 \mathrm{~km}$ depth were computed over a $200 \mathrm{~km}$ wide zone centered on the perpendicular projection of the kimberlite occurrences onto the $2 \mathrm{D}$ profile ( $\sim 20 \mathrm{~km}$ and $\sim 160 \mathrm{~km}$ projection distances for Jagersfontein and Gibeon respectively). Average resistivities observed at $100 \mathrm{~km}$ depth are $5,800 \Omega \mathrm{m}$ 


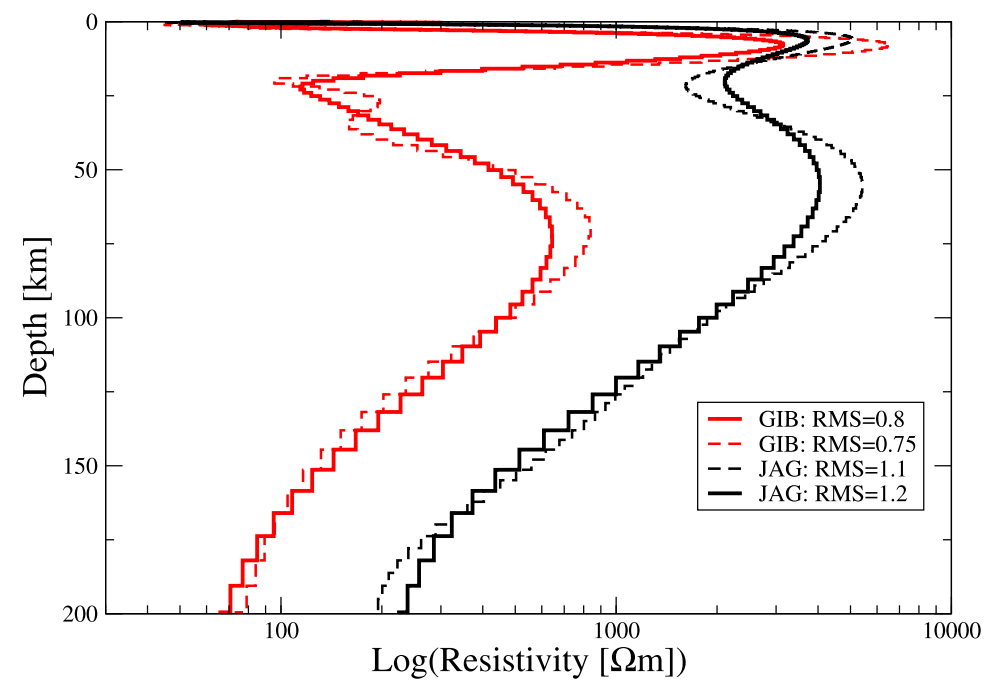

Figure 8. Best fitting Occam [Constable et al., 1987] 1-D models to the averaged data from kim015 (Figure 7a) and gib012 (Figure 7b) for minimum RMS misfit (dashed lines) and approx. 10\% higher misfit (solid lines).

( $\log _{10}$ (conductivity) of $-3.76 \pm 0.43(1 \sigma) \log$ units) and $840 \Omega \mathrm{m}$ ( $\log _{10}$ (conductivity) of $-2.92 \pm$ $0.22 \log$ units) for Jagersfontein and Gibeon respectively. Given the relatively large projection distance in the case of the Gibeon field, some uncertainty exists in assuming both a perpendicular projection onto the profile and little geological heterogeneity over the projection distance. To address the former uncertainty, and to some extent the latter, the Gibeon field was projected onto the profile parallel to the observed geoelectric strike direction (projection azimuth $25^{\circ} \mathrm{E}$ of $\mathrm{N}$, versus $40^{\circ} \mathrm{E}$ of $\mathrm{N}$ for the perpendicular projection), yielding an average resistivity at $100 \mathrm{~km}$ depth of $660 \Omega \mathrm{m}\left(\log _{10}\right.$ (conductivity) of $-2.82 \pm 0.19 \log$ units) and, arguably, a more geologically justifiable measurement.

[59] In summary, the approximate depth mapping and the formal 1D and 2D modeling yield estimates of $\log _{10}$ (conductivity) below Jagersfontein of $-3.41 \pm 0.20,-3.30$ and $-3.76 \pm 0.43 \mathrm{log}$ units, and for Gibeon of $-2.78 \pm 0.09,-2.65$ and $-2.82 \pm 0.19 \log$ units respectively. All three approaches are consistent and within errors of each other. For the purposes of the comparison with laboratory studies, we take the approximate depth mapping estimates.

\section{Comparison of Field Observations With Laboratory Models}

[60] Our derived $C_{w}-\log _{10}(\sigma)$ points for Jagersfontein and Gibeon are plotted in Figure 5 (yellow square for Jag and purple square for Gib, contours are for proton conduction only) and Figure 6 (green points, total rock conductivity), and, in both cases, the Karato model is too conducting, by an order of magnitude, and the Yoshino and Poe models are not conducting enough, again by an order of magnitude, for a water content of $80 \mathrm{ppm}$ and the temperature estimates we have assumed. Note in Figure 6 that the whole rock calculations (solid lines) are within one quarter of a decade or less, i.e., the error of the resistivity measurement, of the resistivity of the olivine-only calculations (dashed lines). Considerations of the appropriate water model for the pyroxenes and garnet, and of iron content and composition, are all secondary compared to the olivine proton conduction model. Hence we focus on improving the parameters of the olivine proton conduction model.

[61] For Jagersfontein, using the mean parameters for olivine listed in Table 1 the Karato water model is certainly far too conductive; for $\log _{10}$ (conductivity) of -3.41 one only needs $8 \mathrm{ppm}$ water, an unrealistically low number. The Yoshino and Poe models though are too resistive for the reported water contents; a $\log _{10}$ (conductivity) of -3.41 requires $250 \mathrm{ppm}$ of water in the olivine for the Poe model and $350 \mathrm{ppm}$ for the Yoshino model, both of which are more than a factor of three higher than the reported water content. Similarly for Gibeon with a $\log _{10}$ (conductivity) of -2.78 , the Karato model would predict a water content in olivine of $10 \mathrm{ppm}$, the Poe model 320 ppm, and the Yoshino model $550 \mathrm{ppm}$, all of which are unrealistic.

[62] Figure 5 shows the trade-offs between temperature and water content for the three models, with Figure 5a for the Karato model and parameters, 
Table 6. Karato Model Parameters for Olivine Conductivity Fitted to Jagersfontein and Gibeon Observed Resistivities to Within $\sigma / 10$ (2,450-2,700 $\Omega \mathrm{m}$ and 590-620 $\Omega \mathrm{m}$ Respectively), $\sigma / 4$ (2,000-3,250 $\Omega \mathrm{m}$ and 550$670 \Omega \mathrm{m}$ Respectively) and $\sigma / 2\left(1,600-4,100 \Omega \mathrm{m}\right.$ and 500-750 $\Omega \mathrm{m}$ Respectively) Bounds for $C_{w}=80 \mathrm{ppm}$ $( \pm 10)$ Water at Temperatures $t$ of $740^{\circ} \mathrm{C}$ and $850^{\circ} \mathrm{C}\left(\right.$ Both $\pm 25^{\circ} \mathrm{C}$ ) Respectively From 1,000,000 Realizations by Monte Carlo Random Selection From Six Gaussian Distributed Parameters $\log \left(\sigma_{0}\right), r, \Delta H_{w e t}, C_{w}, t_{J a g}$ and $t_{G i b}{ }^{\mathrm{a}}$

\begin{tabular}{|c|c|c|c|c|c|c|}
\hline & $\%$ Accept. & $\begin{array}{c}\log _{10} \\
\left(\sigma_{0}[\mathrm{~S} / \mathrm{m}]\right)\end{array}$ & $r$ & $\begin{array}{c}\Delta H_{w e t} \\
(\mathrm{eV})\end{array}$ & $\begin{array}{l}\text { Jagersfontein } \log _{10} \\
\qquad(\sigma[\mathrm{S} / \mathrm{m}])\end{array}$ & $\begin{array}{l}\text { Gibeon } \log _{10} \\
\qquad(\sigma[\mathrm{S} / \mathrm{m}])\end{array}$ \\
\hline $\begin{array}{l}\text { Wang et al. [2006] parameters } \\
\text { and SAMTEX observations }\end{array}$ & - & $3.0 \pm 0.4$ & $\mathbf{0 . 6 2} \pm \mathbf{0 . 1 5}$ & $\mathbf{0 . 8 7} \pm \mathbf{0 . 0 5}$ & $-3.41 \pm 0.20$ & $-2.78 \pm 0.09$ \\
\hline \multicolumn{7}{|c|}{ Within $\sigma / 10$} \\
\hline Jagersfontein & 1.1 & $2.63 \pm 0.29$ & $0.73 \pm 0.13$ & $0.90 \pm 0.05$ & $-3.41 \pm 0.01$ & - \\
\hline Gibeon & 0.75 & $2.72 \pm 0.28$ & $0.71 \pm 0.12$ & $0.89 \pm 0.05$ & - & $-2.78 \pm 0.005$ \\
\hline Jagersfontein and Gibeon & 0.03 & $2.70 \pm 0.26$ & $0.70 \pm 0.12$ & $0.91 \pm 0.04$ & $-3.41 \pm 0.01$ & $-2.78 \pm 0.005$ \\
\hline \multicolumn{7}{|c|}{ Within $\sigma / 4$} \\
\hline Jagersfontein & 2.8 & $2.63 \pm 0.29$ & $0.73 \pm 0.13$ & $0.90 \pm 0.04$ & $-3.41 \pm 0.03$ & - \\
\hline Gibeon & 1.9 & $2.71 \pm 0.28$ & $0.71 \pm 0.12$ & $0.89 \pm 0.05$ & - & $-2.78 \pm 0.01$ \\
\hline Jagersfontein and Gibeon & 0.2 & $2.71 \pm 0.28$ & $0.71 \pm 0.13$ & $0.90 \pm 0.04$ & $-3.40 \pm 0.03$ & $-2.78 \pm 0.01$ \\
\hline \multicolumn{7}{|c|}{ Within $\sigma / 2$} \\
\hline Jagersfontein & 5.7 & $2.63 \pm 0.29$ & $0.73 \pm 0.13$ & $0.90 \pm 0.05$ & $-3.40 \pm 0.06$ & - \\
\hline Gibeon & 3.8 & $2.71 \pm 0.28$ & $0.70 \pm 0.12$ & $0.90 \pm 0.05$ & - & $-2.78 \pm 0.03$ \\
\hline Jagersfontein and Gibeon & 0.8 & $2.71 \pm 0.28$ & $0.71 \pm 0.13$ & $0.90 \pm 0.04$ & $-3.38 \pm 0.05$ & $-2.78 \pm 0.03$ \\
\hline
\end{tabular}

${ }^{a}$ Each of the three runs was independent. Bold values are those of Wang et al. [2006].

Figure $5 \mathrm{~b}$ for the Yoshino/Poe model and Yoshino parameters, and Figure $5 \mathrm{c}$ for the Yoshino/Poe model and averaged Poe parameters, plus a fourth model we develop below that combines the Karato and Yoshino/Poe models (Figure 5d). Even assuming that both our temperature and water content estimates are seriously in error, there is no reasonable combination of temperature and water content for any of the three laboratory models that are an acceptable fit to the two resistivity data points.

\subsection{Monte-Carlo Model Fitting}

[63] The three parameters for the Karato olivine water model, $\log _{10}\left(\sigma_{0}\right), r$, and $\Delta H_{\text {wet }}$, have rather large standard deviations in Wang et al. [2006] (Table 1), so one can test if realizations taken randomly from the statistical distributions of the parameters fit the resistivity observations from Jagersfontein and Gibeon. Undertaking a Monte-Carlo stochastic modeling exercise by generating $1,000,000$ realizations for the five parameters randomly sampled from Gaussian distributions with means and standard deviations of

$$
\begin{aligned}
\log _{10}\left(\sigma_{0}\right) & =3.0 \pm 0.4, \\
r & =0.62 \pm 0.15, \\
\Delta H_{w e t} & =0.87 \pm 0.05(\mathrm{eV}), \\
C_{w} & =80 \pm 10(\mathrm{ppm}), \\
\text { and } T & =740 \pm 25\left({ }^{\circ} \mathrm{C}, \text { Jagersfontein }\right) \\
\text { and } T & =850 \pm 25\left({ }^{\circ} \mathrm{C}, \text { Gibeon }\right),
\end{aligned}
$$

yields best fit models listed in Table 6 fitting to within one tenth, one quarter and one half of the standard deviations of $\log _{10}$ (conductivity) of $-3.41 \pm 0.20$ and $-2.78 \pm 0.09$ respectively for Jagersfontein and Gibeon. Note that the few found within $\sigma / 10$ are all close to the one sigma bounds of the experimental data of Wang et al. [2006], and the summed difference from the Wang et al. parameters is $2 \sigma$. Adopting the field observation refined values of $\log _{10}\left(\sigma_{0}\right)=$ 2.70, $r=0.70$, and $\Delta H_{\text {wet }}=0.91$ for olivine and the existing values for the other minerals yields the dashed green curves in Figure 6.

[64] Our strategy of "calibrating" the proton conduction model parameters $\log _{10}\left(\sigma_{0}\right), r$, and $\Delta H_{\text {wet }}$ for olivine-only against observed whole rock data is justifiable as the error bounds on the observed conductivity data are significantly greater than the differences between the "olivine only" and "assemblage" models in Figure 6. The observed data available (two points each of three data) are also too few to allow the proton conduction model parameters to be determined or calibrated independently for the pyroxenes and garnet as well - this could be potentially introduced in the future when more observed data points are available.

[65] Undertaking this stochastic exercise for the Yoshino model and parameters $\log _{10}\left(\sigma_{0}\right), \Delta H_{\text {wet }}$, and $\alpha$ yields for $\sigma / 10$ only 11 acceptable models of the one million tested, with the parameters given in Table 7. These mean model parameters lie though 
Table 7. Yoshino Model Parameters for Olivine Conductivity Fitted to Jagersfontein and Gibeon Observed Resistivities to Within $\sigma / 10$ (2,450 - 2,700 $\Omega \mathrm{m}$ and $590-620 \Omega \mathrm{m}$ Respectively), $\sigma / 4$ (2,000 - 3,250 $\Omega \mathrm{m}$ and $550-$ $670 \Omega \mathrm{m}$ Respectively) and $\sigma / 2\left(1,600-4,100 \Omega \mathrm{m}\right.$ and $500-750 \Omega \mathrm{m}$ Respectively) Bounds for $C_{w}=80 \mathrm{ppm}( \pm 10)$ Water at Temperatures $t$ of $740^{\circ} \mathrm{C}$ and $850^{\circ} \mathrm{C}$ (Both $\pm 25^{\circ} \mathrm{C}$ ) Respectively From 1,000,000 Realizations by Monte Carlo Random Selection From Six Gaussian Distributed Parameters $\log \left(\sigma_{0}\right), \Delta H_{w e t}, \alpha, C_{w}, t_{J a g}$ and $t_{G i b}{ }^{\mathrm{a}}$

\begin{tabular}{|c|c|c|c|c|c|c|}
\hline & $\%$ Accept. & $\begin{array}{c}\log _{10} \\
\left(\sigma_{0}[\mathrm{~S} / \mathrm{m}]\right)\end{array}$ & $\begin{array}{c}\Delta H_{w e t} \\
(\mathrm{eV})\end{array}$ & $\alpha$ & $\begin{array}{l}\text { Jagersfontein } \log _{10} \\
(\sigma[\mathrm{S} / \mathrm{m}])\end{array}$ & $\begin{array}{l}\text { Gibeon } \log _{10} \\
\quad(\sigma[\mathrm{S} / \mathrm{m}])\end{array}$ \\
\hline $\begin{array}{l}\text { Yoshino et al. parameters } \\
\text { and SAMTEX observations }\end{array}$ & - & $1.9 \pm 0.44$ & $0.92 \pm 0.04$ & $\mathbf{0 . 1 6} \pm \mathbf{0 . 0 2}$ & $-3.41 \pm 0.20$ & $-2.78 \pm 0.09$ \\
\hline \multicolumn{7}{|c|}{ Within $\sigma / 10$} \\
\hline Jagersfontein & 0.2 & $2.84 \pm 0.19$ & $0.85 \pm 0.04$ & $0.16 \pm 0.02$ & $-3.41 \pm 0.01$ & - \\
\hline Gibeon & 0.02 & $3.07 \pm 0.18$ & $0.85 \pm 0.04$ & $0.16 \pm 0.02$ & - & $-2.78 \pm 0.005$ \\
\hline Jagersfontein and Gibeon & 0.001 & $3.13 \pm 0.18$ & $0.87 \pm 0.03$ & $0.17 \pm 0.02$ & $-3.40 \pm 0.01$ & $-2.78 \pm 0.005$ \\
\hline \multicolumn{7}{|c|}{ Within $\sigma / 4$} \\
\hline Jagersfontein & 0.4 & $2.84 \pm 0.20$ & $0.85 \pm 0.04$ & $0.16 \pm 0.02$ & $-3.41 \pm 0.03$ & - \\
\hline Gibeon & 0.05 & $3.06 \pm 0.18$ & $0.85 \pm 0.04$ & $0.16 \pm 0.02$ & - & $-2.78 \pm 0.01$ \\
\hline Jagersfontein and Gibeon & 0.007 & $3.05 \pm 0.20$ & $0.86 \pm 0.04$ & $0.16 \pm 0.02$ & $-3.40 \pm 0.03$ & $-2.78 \pm 0.01$ \\
\hline \multicolumn{7}{|c|}{ Within $\sigma / 2$} \\
\hline Jagersfontein & 0.9 & $2.84 \pm 0.21$ & $0.85 \pm 0.04$ & $0.16 \pm 0.02$ & $-3.43 \pm 0.06$ & - \\
\hline Gibeon & 0.1 & $3.05 \pm 0.18$ & $0.84 \pm 0.04$ & $0.16 \pm 0.02$ & - & $-2.78 \pm 0.03$ \\
\hline Jagersfontein and Gibeon & 0.03 & $3.04 \pm 0.20$ & $0.86 \pm 0.04$ & $0.16 \pm 0.02$ & $-3.38 \pm 0.06$ & $-2.79 \pm 0.03$ \\
\hline
\end{tabular}

${ }^{a}$ Each of the three runs was independent. Bold values are those of Yoshino et al. [2009].

$4.5 \sigma$ away from the laboratory-derived values, and are thus highly unlikely to be explainable by laboratory random error. Similarly for the Poe model (Table 8); the averages of the 14 models of the one million tested that fit the Jagersfontein and Gibeon data to within $\sigma / 10$ lie $17 \sigma$ away from the laboratorydetermined values.
[66] The Karato, Yoshino and Poe model parameters are in reasonably close agreement in the estimates of the pre-exponent term, $\log _{10}\left(\sigma_{0}\right)$, and the activation energy term, $\Delta H_{\text {wet }}$, with means and standard deviations of $3.07 \pm 0.20$ and $0.90 \pm 0.03$ respectively (Table 9). Disagreement lies in the value of the exponent on the water content, $r$, from

Table 8. Poe Model Parameters for Olivine Conductivity Fitted to Jagersfontein and Gibeon Observed Resistivities to Within $\sigma / 10$ (2,450-2,700 $\Omega \mathrm{m}$ and 590-620 $\Omega \mathrm{m}$ Respectively), $\sigma / 4(2,000-3,250 \Omega \mathrm{m}$ and 550-670 $\Omega \mathrm{m}$ Respectively) and $\sigma / 2\left(1,600-4,100 \Omega \mathrm{m}\right.$ and 500-750 $\Omega \mathrm{m}$ Respectively) Bounds for $C_{w}=80 \mathrm{ppm}( \pm 10)$ Water at Temperatures $t$ of $740^{\circ} \mathrm{C}$ and $850^{\circ} \mathrm{C}\left(\right.$ Both $\pm 25^{\circ} \mathrm{C}$ ) Respectively From 1,000,000 Realizations by Monte Carlo Random Selection From Six Gaussian Distributed Parameters $\log \left(\sigma_{0}\right), \Delta H_{w e t}, \alpha, C_{w}, t_{J a g}$ and $t_{G i b}{ }^{a}$

\begin{tabular}{|c|c|c|c|c|c|c|}
\hline & $\%$ Accept. & $\begin{array}{c}\log _{10} \\
\left(\sigma_{0}[\mathrm{~S} / \mathrm{m}]\right)\end{array}$ & $\begin{array}{l}\Delta H_{\text {wet }} \\
(\mathrm{eV})\end{array}$ & $\alpha$ & $\begin{array}{l}\text { Jagersfontein } \log _{10} \\
(\sigma[\mathrm{S} / \mathrm{m}])\end{array}$ & $\begin{array}{l}\text { Gibeon } \log _{10} \\
(\sigma[\mathrm{S} / \mathrm{m}])\end{array}$ \\
\hline \multirow[t]{2}{*}{$\begin{array}{l}\text { Poe et al. averaged parameters } \\
\text { and SAMTEX observations }\end{array}$} & - & $2.35 \pm \mathbf{0 . 1 1}$ & $1.19 \pm 0.035$ & $1.10 \pm 0.055$ & $-3.41 \pm 0.20$ & $-2.78 \pm 0.09$ \\
\hline & \multicolumn{4}{|c|}{ Within $\sigma / 10$} & & \\
\hline Jagersfontein & 0.2 & $3.25 \pm 0.21$ & $0.93 \pm 0.04$ & $1.10 \pm 0.02$ & $-3.41 \pm 0.01$ & - \\
\hline Gibeon & 0.03 & $3.43 \pm 0.19$ & $0.93 \pm 0.04$ & $1.10 \pm 0.02$ & - & $-2.78 \pm 0.005$ \\
\hline \multirow[t]{2}{*}{ Jagersfontein and Gibeon } & 0.001 & $3.38 \pm 0.19$ & $0.92 \pm 0.03$ & $1.10 \pm 0.02$ & $-3.41 \pm 0.01$ & $-2.78 \pm 0.005$ \\
\hline & \multicolumn{4}{|c|}{ Within $\sigma / 4$} & & \\
\hline Jagersfontein & 0.5 & $3.24 \pm 0.21$ & $0.93 \pm 0.04$ & $1.10 \pm 0.02$ & $-3.41 \pm 0.03$ & - \\
\hline Gibeon & 0.09 & $3.42 \pm 0.19$ & $0.93 \pm 0.04$ & $1.10 \pm 0.02$ & - & $-2.78 \pm 0.01$ \\
\hline \multirow[t]{2}{*}{ Jagersfontein and Gibeon } & 0.02 & $3.41 \pm 0.18$ & $0.93 \pm 0.04$ & $1.10 \pm 0.02$ & $-3.40 \pm 0.03$ & $-2.78 \pm 0.01$ \\
\hline & \multicolumn{4}{|c|}{ Within $\sigma / 2$} & & \\
\hline Jagersfontein & 1.1 & $3.24 \pm 0.21$ & $0.93 \pm 0.04$ & $1.10 \pm 0.02$ & $-3.43 \pm 0.06$ & - \\
\hline Gibeon & 0.2 & $3.42 \pm 0.19$ & $0.93 \pm 0.04$ & $1.10 \pm 0.02$ & - & $-2.78 \pm 0.03$ \\
\hline Jagersfontein and Gibeon & 0.07 & $3.40 \pm 0.19$ & $0.93 \pm 0.04$ & $1.10 \pm 0.02$ & $-3.39 \pm 0.06$ & $-2.79 \pm 0.03$ \\
\hline
\end{tabular}

${ }^{\mathrm{a}}$ Each of the three runs was independent. Bold values are those of Poe et al. [2010]. 
Table 9. Parameters Fitted to Jagersfontein and Gibeon Observed Resistivities to Within $\sigma / 10(2,450-2,700 \Omega \mathrm{m}$ and 590-620 $\Omega \mathrm{m}$ Respectively), $\sigma / 4(2,000-3,250 \Omega \mathrm{m}$ and 550-670 $\Omega \mathrm{m}$ Respectively) and $\sigma / 2(1,600-4,100 \Omega \mathrm{m}$ and 500-750 $\Omega \mathrm{m}$ Respectively) Bounds for $C_{w}=80 \mathrm{ppm}( \pm 5)$ Water at Temperatures $t$ of $740^{\circ} \mathrm{C}$ and $850^{\circ} \mathrm{C}$ (Both $\pm 10^{\circ} \mathrm{C}$ ) Respectively From 10,000,000 Realizations by Monte Carlo Random Selection From Five Gaussian Distributed Parameters $\log \left(\sigma_{0}\right), \Delta H_{w e t}, C_{w}, t_{J a g}$ and $t_{G i b}$ and Two Uniformly Distributed Parameters, $r$ and $\alpha^{\mathrm{a}}$

\begin{tabular}{|c|c|c|c|c|c|c|c|}
\hline & $\%$ & $\begin{array}{c}\log _{10} \\
\left(\sigma_{0}[\mathrm{~S} / \mathrm{m}]\right)\end{array}$ & $r$ & $\begin{array}{c}\Delta H_{\text {wet }} \\
(\mathrm{eV})\end{array}$ & $\alpha$ & $\begin{array}{c}\text { Jagersfontein } \log _{10} \\
(\sigma[\mathrm{S} / \mathrm{m}])\end{array}$ & $\begin{array}{l}\text { Gibeon } \log _{10} \\
(\sigma[\mathrm{S} / \mathrm{m}])\end{array}$ \\
\hline $\begin{array}{c}\text { Karato model } \\
\text { best fitting } \\
\text { parameters }\end{array}$ & - & $2.70 \pm 0.26$ & $0.70 \pm 0.12$ & $0.91 \pm 0.04$ & 0.0 (implicit) & $-3.41 \pm 0.20$ & $-2.78 \pm 0.09$ \\
\hline $\begin{array}{l}\text { Yoshino model } \\
\text { best fitting } \\
\text { parameters }\end{array}$ & - & $3.13 \pm 0.18$ & 1.0 (implicit) & $0.87 \pm 0.03$ & $0.17 \pm 0.02$ & & \\
\hline $\begin{array}{l}\text { Poe AV model } \\
\text { best fitting } \\
\text { parameters }\end{array}$ & - & $3.38 \pm 0.19$ & 1.0 (implicit) & $0.92 \pm 0.03$ & $1.10 \pm 0.02$ & & \\
\hline $\begin{array}{l}\text { Parameters adopted } \\
\text { for distributions }\end{array}$ & - & $\begin{array}{l}3.07 \pm \mathbf{0 . 2 0} \\
\text { (Gaussian) }\end{array}$ & $\begin{array}{l}0.70-1.0 \\
\quad \text { (uniform) }\end{array}$ & $\begin{array}{r}\mathbf{0 . 9 0} \pm \mathbf{0 . 0 3} \\
\quad \text { (Gaussian) }\end{array}$ & $\begin{array}{l}0.0-1.1 \\
\quad \text { (uniform) }\end{array}$ & & \\
\hline \multicolumn{8}{|c|}{ Within $\sigma / 10$} \\
\hline Jagersfontein & 1.01 & $2.91 \pm 0.16$ & $0.92 \pm 0.07$ & $0.88 \pm 0.03$ & $0.18 \pm 0.15$ & $-3.41 \pm 0.01$ & - \\
\hline Gibeon & 0.93 & $2.96 \pm 0.17$ & $0.90 \pm 0.07$ & $0.86 \pm 0.04$ & $0.26 \pm 0.19$ & - & $-2.78 \pm 0.005$ \\
\hline $\begin{array}{l}\text { Jagersfontein } \\
\text { and Gibeon }\end{array}$ & 0.00066 & $3.05 \pm 0.16$ & $0.86 \pm 0.08$ & $0.91 \pm 0.03$ & $0.09 \pm 0.08$ & $-3.40 \pm 0.01$ & $-2.78 \pm 0.005$ \\
\hline \multicolumn{8}{|c|}{ Within $\sigma / 4$} \\
\hline Jagersfontein & 2.54 & $2.91 \pm 0.16$ & $0.92 \pm 0.07$ & $0.88 \pm 0.03$ & $0.18 \pm 0.15$ & $-3.41 \pm 0.03$ & - \\
\hline Gibeon & 2.32 & $2.96 \pm 0.17$ & $0.90 \pm 0.07$ & $0.86 \pm 0.04$ & $0.26 \pm 0.19$ & - & $-2.78 \pm 0.01$ \\
\hline $\begin{array}{l}\text { Jagersfontein } \\
\text { and Gibeon }\end{array}$ & 0.0094 & $3.03 \pm 0.17$ & $0.86 \pm 0.08$ & $0.90 \pm 0.03$ & $0.13 \pm 0.12$ & $-3.38 \pm 0.02$ & $-2.79 \pm 0.01$ \\
\hline \multicolumn{8}{|c|}{ Within $\sigma / 2$} \\
\hline Jagersfontein & 5.14 & $2.91 \pm 0.17$ & $0.91 \pm 0.07$ & $0.88 \pm 0.03$ & $0.19 \pm 0.15$ & $-3.40 \pm 0.06$ & - \\
\hline Gibeon & 4.65 & $2.96 \pm 0.17$ & $0.90 \pm 0.07$ & $0.86 \pm 0.04$ & $0.26 \pm 0.19$ & - & $-2.78 \pm 0.03$ \\
\hline $\begin{array}{l}\text { Jagersfontein } \\
\text { and Gibeon }\end{array}$ & 0.19 & $3.01 \pm 0.16$ & $0.88 \pm 0.08$ & $0.89 \pm 0.03$ & $0.16 \pm 0.13$ & $-3.33 \pm 0.02$ & $-2.80 \pm 0.02$ \\
\hline
\end{tabular}

${ }^{\mathrm{a}}$ Each of the three runs was independent. Bold values are those adopted for the distributions.

0.70 (Karato) to 1.0 (Yoshino and Poe), and on the additional activation energy term, $\alpha C^{\text {l/3 }}$, with $\alpha$ from 0.0 (Karato) to 0.17 (Yoshino) to 1.1 (Poe). We have three knowns, namely olivine water content of $80 \mathrm{ppm}$ and $\log _{10}$ (conductivity) of -3.41 for Jagersfontein, and $\log _{10}$ (conductivity) of -2.78 for Gibeon, one assumed datum, olivine water content of $80 \mathrm{ppm}$ for Gibeon, and two derived data, the ambient temperature at $100 \mathrm{~km}$ beneath Jagersfontein and Gibeon. We thus have six knowns and four unknowns, two of which $\left(\log \left(\sigma_{0}\right)\right.$ and $\left.\Delta H_{\text {wet }}\right)$ are tightly bounded and, we assume, Gaussian distributed, and the other two ( $r$ and $\alpha$ ) are poorly bounded and for which we must assume uniform distributions in the ranges $0.7-1.0$ and $0.0-1.1$ respectively.

[67] Undertaking the same Monte Carlo exercise, but with tighter bounds on water content ( $\pm 5 \mathrm{ppm}$ ) and temperature $\left( \pm 10^{\circ} \mathrm{C}\right)$, for 10 million random realizations taken from the parameter distributions yields the statistics of the acceptable solutions given in Table 9 of $\log _{10}\left(\sigma_{0}\right)=3.05 \pm 0.16, r=$ $0.86 \pm 0.08, \Delta H_{\text {wet }}=0.91 \pm 0.03$, and $\alpha=0.09 \pm$ 0.07 for olivine proton conduction for the 66 models found that fit both the Jagersfontein and Gibeon MT data to within $\sigma / 10$ of their statistical limits. Conductivities from these model parameters are shown as the solid green curves in Figure 6, and for temperature and water content variation in Figure $5 \mathrm{~d}$.

\section{Discussion}

[68] Both the petrological and electromagnetic observations infer the existence of water in the upper lithosphere, with kimberlitic xenoliths yielding values around $60-100 \mathrm{ppm}$ in olivine and higher in the pyroxenes (200 ppm and $300 \mathrm{ppm}$ for Opx and Cpx respectively). Of the three water models defined by laboratory measurements, that of Karato is too conductive, and those of Yoshino and Poe are too resistive, all by an order of magnitude or more. Searching 
stochastically for model parameters acceptable to the observations (Jagersfontein and Gibeon resistivities, water contents and temperatures) yields narrowly defined values for $\log _{10}\left(\sigma_{0}\right), r, \Delta H_{\text {wet }}$, and $\alpha$. The determined values define a combination of the Karato and Yoshino/Poe models, with $\log _{10}\left(\sigma_{0}\right)$ of 3.05 , which is close to the Karato value (3.0), $r$ of 0.86 , which lies between the Karato value (0.62) and unity (i.e., not considered) of Yoshino and Poe, $\Delta H_{\text {wet }}$ of 0.91 , which is at the Yoshino value (0.92) and within error of the Karato estimate (0.87), and $\alpha$ of 0.09 lying between the Karato value $(0.0$, i.e., not considered) and the Yoshino value (0.16). It must, however, be borne in mind that the field-observed calibrations have been undertaken at "barely damp" water contents, of order 60-100 ppm, and $\alpha$ becomes important at the higher water contents studied by Poe.

[69] In this analysis we assume that our temperature estimates are reasonable. As shown in Figures 4 and 5, temperature errors of order $50^{\circ} \mathrm{C}$ introduce $0.2 \mathrm{log}$ unit error in estimates of proton conductivity. To explain the observations with the laboratory data, the temperature estimates would have to be underestimated by $200^{\circ} \mathrm{C}$, which is unreasonable and inconsistent with all other observables [see Fullea et al., 2011].

[70] We further assume that the water contents reported for the Kaapvaal Craton [Peslier et al., 2010b; Baptiste et al., 2012] are reasonably accurate and are unbiased by water loss. We cannot though exclude the possibility, however faint, that despite the flat hydrogen profiles in almost all olivines recovered from kimberlitic xenoliths there has been water loss during escape in a manner that yields universally flat diffusion profiles. The Karato model and model parameters cannot be fit to our data for water contents beyond some $10 \mathrm{ppm}$, so are unaffected by such an argument. The Yoshino model and model parameters infer some $350 \mathrm{ppm}$ water in olivine to fit the Jagersfontein resistivity, and some $550 \mathrm{ppm}$ to fit the Gibeon resistivity, both of which are certainly unrealistically high. The averaged Poe model parameters requires $250 \mathrm{ppm}$ and $320 \mathrm{ppm}$ respectively, which is a factor of $3 \times$ greater than Peslier et al.'s [2010b] estimate for Jagersfontein and $4 \times$ greater than our assumed water content for Gibeon. Even admitting underestimation of water contents in olivines, such factors are, we believe, also too high.

[71] Last, we cannot exclude the alternate possibility that indeed either the Poe or Yoshino model parameters are correct, but there exists another exotic conducting phase, currently unknown, that increases conductivity by an order of magnitude yielding the observations shown in Figures 5 and 6. We can reasonable exclude enhanced polaron conduction; our temperature estimates would have to be in error by over $200^{\circ} \mathrm{C}$, which is highly unlikely as it would require significant heating since kimberlite eruption $80 \mathrm{Myr}$ ago and is inconsistent with the study of Fullea et al. [2011], among others. Carbon, at depths above the graphite-diamond stability field (approx. $150 \mathrm{~km}$ beneath cratons), has long been proposed to enhance mantle electrical conductivity [Duba and Shankland, 1982], but given its very high conductivity $\left(>10^{6} \mathrm{~S} / \mathrm{m}\right)$ it would have to be present at extremely low fractions and that would question interconnectivity [Watson et al., 2010]. Spratt et al. [2009] discuss possible candidates for enhancing conductivity above that expected for dry minerals, and exclude almost all of them. They appeal to the speculative results of ten Grotenhuis et al. [2004] regarding grain boundary conduction in fine grained olivine to explain their observations of reduced resistivity within the Wopmay Orogen compared to the bounding cratons. Given typical grain sizes observed in xenolith samples $(1 \mathrm{~cm})$, this explanation can also be excluded. Finally, interstitial iron sulfides precipitated from metasomatic fluids can reduce resistivity [Ducea and Park, 2000], but again high volumes are required $(>1 \%)$ to ensure interconnectivity [Watson et al., 2010] and such sulfides are not seen in xenolith material.

[72] In conclusion, given the extant data we prefer to adopt the view that the simplest explanation is likely correct, and that the reduced resistivity values we observe in the lithospheric mantle beneath Jagersfontein and Gibeon are best explained in terms of conductivity enhancement by proton conduction from hydrogen diffusion. The difficulty arises that none of the proton conduction models for olivine from the three active laboratories fit the geophysical and petrological observations. However, parameters can be found that fit the basic proton conduction equation (equation (1)) that are within error of the three labs in their estimates of the pre-exponent term and the activation energy term, but are different in the additional terms used by the labs, namely the power term $r$ on the preexponent water content $C_{w}$ used by the Karato group to describe proton hopping, and the $\alpha C_{w}^{1 / 3}$ term used by the Yoshino and Poe groups to 
describe $\mathrm{H}_{2} \mathrm{O}$ concentration-dependent activation enthalpy.

\section{Conclusions}

[73] Geodynamic models of the mantle require accurate and precise knowledge of water content and its distribution, and models without such careful consideration are misleading and are not useful exercises. The effects on viscosity of varying water content are illustrated in $\mathrm{Li}$ et al. [2008], who propose that cratonic material may be recycled into the mantle. Further verification of that model requires mapping of water content of the world's cratonic lithospheres.

[74] Electrical conductivity is a key and unique physical property that can yield valuable information relevant to remote sensing of water in the mantle that is difficult, if not impossible, to determine using any other approach. The water effect on enhancing conductivity is orders of magnitude, compared to minor variation in seismic velocity ( $\sim 1 \%$ reduction for $1 \mathrm{wt} \%$ water [Karato, 2006]) of the same order as effects from possible compositional variation (to which conductivity is essentially insensitive, see Jones et al. [2009a]). The difficulty that seismology has in inferring water content is exemplified by the comparison discussed in Karato [2011] of water content estimates in the mantle transition zone (MTZ) beneath eastern Asia, with one technique suggesting the MTZ is water-poor, and another suggesting it is water-rich (see Introduction). For the cratonic lithosphere, the difference between dry and "slightly damp" (i.e., water contents of order $100 \mathrm{ppm}$ ) are impossible to detect using seismology, whereas careful, welldesigned EM methods can easily detect the one or more orders of magnitude increase in conductivity (Figure 1).

[75] The laboratory studies on wet mantle minerals discussed herein by Karato's, Yoshino's and Poe's groups are providing important and critical information, and their work is needed. However, the disparity in the observations and the contention between the labs is, unfortunately, resulting in low appreciation and acceptance by the geoscience community of the key role electrical conductivity observations can play in constraining water content in the mantle. The three labs have to reconcile their differences, and simultaneously we need to have more geophysical-petrological controls to calibrate the lab results. This latter point is highlighted by Figure 5 that shows the derived conductivity for the three models, plus the model defined herein, for possible lithospheric temperatures and water contents. The $T-C_{w}$ model space is large, and herein we are only sampling it at two locations, namely those of Jagersfontein and Gibeon.

[76] Based on $T-C_{w^{-}} \sigma$ data from two localities, i.e., 6 data, we fit a four parameter Arrhenius model of proton conduction of the general form given in equation (1) using Monte-Carlo stochastic modeling. We assume that the two better-determined parameters, $\log _{10}\left(\sigma_{0}\right)$ and $\Delta H_{\text {wet }}$, are Gaussian distributed in rather narrow ranges defined by the laboratory experiments, whereas the more difficult to determine parameters, $r$ and $\alpha$, are uniformly distributed with broader ranges, also defined by the experiments. Of the ten million realizations generated from the four distributions, the 66 that fit the two conductivity observations to within $\sigma / 10$ have values of $\log _{10}\left(\sigma_{0}\right)=3.05 \pm 0.16, r=0.86 \pm 0.08$, $\Delta H_{\text {wet }}=0.91 \pm 0.03$, and $\alpha=0.09 \pm 0.07$. This model must be tested through application to other areas where we have sufficient petrological and geophysical knowledge.

\section{Appendix A}

[77] A note for the non-specialists (like us!), one must be careful when comparing various determined estimates of water content by different experimentalists depending on the calibration used. The three main ones are the Paterson calibration [Paterson, 1982], the Libowitzky and Rossman calibration [Libowitzky and Rossman, 1997], and the Bell calibration [Bell et al., 2003] (which was developed to accommodate crystal anisotropy although we do not consider anisotropic effects), yield values that are factors of up to 3 different (with Bell being the highest).

[78] Also, water concentration is reported by different authors from different communities with different units. Geochemists and petrologists mostly use weight percent (wt\%) and parts per million by weight $(\mathrm{ppm} w \mathrm{wt}=10,000 \times \mathrm{wt} \%)$. On the other hand, in the mineral physics community $\mathrm{H} / 10^{6} \mathrm{Si}$ and $\mathrm{ppm} \mathrm{H} / \mathrm{Si}$ are more popular. For an olivine with a mantle composition (Fo90), 1 ppm $\mathrm{H}_{2} \mathrm{O}$ wt $=$ $16.35 \mathrm{H} / 10^{6} \mathrm{Si}$ (read 16.35 atoms of $\mathrm{H}$ per $10^{6}$ atoms of silicon). It can also be presented as $1 \mathrm{ppm} \mathrm{H}_{2} \mathrm{O}$ $\mathrm{wt}=16.35$ at $\mathrm{ppm} \mathrm{H} / \mathrm{Si}$ (atomic $\mathrm{ppm}$ of $\mathrm{H}$ per atom of silicon). Those units are commonly used in studies quantifying water by Fourier transform infrared spectroscopy. When analyses are obtained by SIMS (secondary ion mass spectrometry), the 
detection of the chemical composition for the calibration is often presented using ratio of counts number (cts) as, for example, ${ }^{16} \mathrm{O}^{1} \mathrm{H} /{ }^{30} \mathrm{Si}$ (cts) or ${ }^{1} \mathrm{H} /{ }^{30} \mathrm{Si}$ (cts). One should always keep in mind that the conversion factor to go from ppm $\mathrm{H}_{2} \mathrm{O}$ wt to $\mathrm{H} / 10^{6} \mathrm{Si}$ or vice versa is density-dependent, then mineral-dependent (see, e.g., Bolfan-Casanova et al. [2000, Table 1] for the calculation method). The conversion factor provided here is only for an olivine with $\mathrm{Fo}_{90}$, for a pure forsterite $\left(\mathrm{Fo}_{100}\right)$, it will be $1 \mathrm{ppm} \mathrm{H}_{2} \mathrm{O}$ wt $=15.65$ at ppm $\mathrm{H} / \mathrm{Si}$. Those values cannot be used for pyroxenes or garnet. However, pressure is expected to have little effect on those conversion coefficients.

\section{Acknowledgments}

[79] The SAMTEX data were acquired through funding provided by the Continental Dynamics program of the U.S. National Science Foundation (grant EAR0455242 to RLE), the South African Department of Science and Technology (grant to South African Council for Geoscience), and Science Foundation Ireland (grant 05/RGP/GEO001 to AGJ) plus financial and/or logistical support provided by all members of the SAMTEX consortium listed in the acknowledgments of Jones et al. [2009b]. Many people strove hard to acquire the SAMTEX data set, and all are very gratefully thanked (see authors and those acknowledged in Jones et al. [2009b]). JF was initially supported by an IRCSET grant to AGJ for the TopoMed project (TopoMed: Plate reorganization in the western Mediterranean: Lithospheric causes and topographic consequences) within the European Science Foundation's TOPOEUROPE EUROCORES (http://www.esf.org/activities/eurocores/ running-programmes/topo-europe.html), and subsequently by an SFI PI grant (10/IN.1/I3022) to AGJ for IRETHERM (www.iretherm.ie). The Editor and Reviewer are gratefully thanked for their positive and constructive reviews of the original version of this manuscript, and Sylvie Demouchy for her instruction (particularly regarding the water concentration units in Appendix A), advice and comments on water in the mantle. Their comments and perspectives caused us to include more material that is, we hope, insightful.

\section{References}

Afonso, J. C., M. Fernandez, G. Ranalli, W. L. Griffin, and J. A. D. Connolly (2008), Integrated geophysical-petrological modeling of the lithosphere and sublithospheric upper mantle: Methodology and applications, Geochem. Geophys. Geosyst., 9, Q05008, doi:10.1029/2007GC001834.

Aubaud, C., E. H. Hauri, and M. M. Hirschmann (2004), Hydrogen partition coefficients between nominally anhydrous minerals and basaltic melts, Geophys. Res. Lett., 31, L20611, doi:10.1029/2004GL021341.

Aubaud, C., A. C. Withers, M. M. Hirschmann, Y. B. Guan, L. A. Leshin, S. J. Mackwell, and D. R. Bell (2007), Intercalibration of FTIR and SIMS for hydrogen measurements in glasses and nominally anhydrous minerals, Am. Mineral., 92(5-6), 811-828, doi:10.2138/am.2007.2248.

Bai, Q., and D. L. Kohlstedt (1992), Substantial hydrogen solubility in olivine and implications for water storage in the mantle, Nature, 357(6380), 672-674, doi:10.1038/ $357672 \mathrm{a} 0$.

Baptiste, V., A. Tommasi, and S. Demouchy (2012), Deformation and hydration of the lithospheric mantle beneath the Kaapvaal craton, South Africa, Lithos, doi:10.1016/j. lithos.2012.05.001, in press.

Bell, D. R. (1992), Water in mantle minerals, Nature, 357(6380), 646-647, doi:10.1038/357646a0.

Bell, D. R., and G. R. Rossman (1992), Water in Earth's mantle - The role of nominally anhydrous minerals, Science, 255(5050), 1391-1397, doi:10.1126/science.255.5050.1391.

Bell, D. R., G. R. Rossman, J. Maldener, D. Endisch, and F. Rauch (2003), Hydroxide in olivine: A quantitative determination of the absolute amount and calibration of the IR spectrum, J. Geophys. Res., 108(B2), 2105, doi:10.1029/ 2001JB000679.

Bell, D. R., G. R. Rossman, and R. O. Moore (2004), Abundance and partitioning of $\mathrm{OH}$ in a high-pressure magmatic system: Megacrysts from the Monastery kimberlite, South Africa, J. Petrol., 45(8), 1539-1564, doi:10.1093/petrology/ egh015.

Beran, M. (1965), Use of vibrational approach to determine bounds for effective permittivity in random media, Nuovo Cimento, 38(2), 771, doi:10.1007/BF02748596.

Beran, M., and J. Molyneux (1966), Use of classical variational principles to determine bounds for effective bulk modulus in heterogeneous media, Q. Appl. Math., 24(2), 107-118.

Berryman, J. G. (1995), Mixture theories for rock properties, in Rock Physics \& Phase Relations: A Handbook of Physical Constants, AGU Ref. Shelf, vol. 3, edited by T. J. Ahrens, pp. 205-228., AGU, Washington, D. C., doi:10.1029/ RF003p0205.

Bolfan-Casanova, N., H. Keppler, and D. C. Rubie (2000), Water partitioning between nominally anhydrous minerals in the $\mathrm{MgO}-\mathrm{SiO}_{2}-\mathrm{H}_{2} \mathrm{O}$ system up to $24 \mathrm{GPa}$ : Implications for the distribution of water in the Earth's mantle, Earth Planet. Sci. Lett., 182(3-4), 209-221, doi:10.1016/S0012821X(00)00244-2.

Brey, G. P., and T. Köhler (1990), Geothermobarometry in 4-phase lherzolites. 2. New thermobarometers, and practical assessment of existing thermobarometers, J. Petrol., 31(6), 1353-1378.

Constable, S. (2006), SEO3: A new model of olivine electrical conductivity, Geophys. J. Int., 166(1), 435-437, doi:10.1111/ j.1365-246X.2006.03041.x.

Constable, S., R. L. Parker, and C. G. Constable (1987), Occam's inversion: A practical algorithm for generating smooth models from electromagnetic sounding data, Geophysics, 52(3), 289-300, doi:10.1190/1.1442303.

Dai, L. D., and S. Karato (2009), Electrical conductivity of orthopyroxene: Implications for the water content of the asthenosphere, Proc. Jpn. Acad., Ser. B, 85(10), 466-475, doi:10.2183/pjab.85.466.

Demouchy, S., S. D. Jacobsen, F. Gaillard, and C. R. Stern (2006), Rapid magma ascent recorded by water diffusion profiles in mantle olivine, Geology, 34(6), 429-432, doi:10.1130/G22386.1.

Duba, A. G., and T. J. Shankland (1982), Free carbon and electrical conductivity in the Earth's mantle, Geophys. Res. Lett., 9(11), 1271-1274, doi:10.1029/GL009i011p01271. 
Ducea, M. N., and S. K. Park (2000), Enhanced mantle conductivity from sulfide minerals, southern Sierra Nevada, California, Geophys. Res. Lett., 27(16), 2405-2408, doi:10.1029/2000GL011565.

Du Frane, W. L., and J. A. Tyburczy (2012), Deuteriumhydrogen exchange in olivine: Implications for point defects and electrical conductivity, Geochem. Geophys. Geosyst., 13, Q03004, doi:10.1029/2011GC003895.

Eaton, D. W., and A. G. Jones (2006), Tectonic fabric of the subcontinental lithosphere: Evidence from seismic, magnetotelluric and mechanical anisotropy-Preface, Phys. Earth Planet. Inter., 158(2-4), 85-91, doi:10.1016/j.pepi. 2006.05.005.

Evans, R. L., et al. (2011), Electrical lithosphere beneath the Kaapvaal craton, southern Africa, J. Geophys. Res., 116, B04105, doi:10.1029/2010JB007883.

Fullea, J., J. C. Afonso, J. A. D. Connolly, M. Fernandez, D. Garcia-Castellanos, and H. Zeyen (2009), LitMod3D: An interactive 3-D software to model the thermal, compositional, density, seismological, and rheological structure of the lithosphere and sublithospheric upper mantle, Geochem. Geophys. Geosyst., 10, Q08019, doi:10.1029/2009GC002391.

Fullea, J., M. R. Muller, and A. G. Jones (2011), Electrical conductivity of continental lithospheric mantle from integrated geophysical and petrological modeling: Application to the Kaapvaal Craton and Rehoboth Terrane, southern Africa, J. Geophys. Res., 116, B10202, doi:10.1029/ 2011JB008544.

Gaetani, G. A., and T. L. Grove (1998), The influence of water on melting of mantle peridotite, Contrib. Mineral. Petrol., 131(4), 323-346, doi:10.1007/s004100050396.

Grant, K., J. Ingrin, J. P. Lorand, and P. Dumas (2007), Water partitioning between mantle minerals from peridotite xenoliths, Contrib. Mineral. Petrol., 154(1), 15-34, doi:10.1007/ s00410-006-0177-1.

Hauri, E. H., G. A. Gaetani, and T. H. Green (2006), Partitioning of water during melting of the Earth's upper mantle at $\mathrm{H}_{2} \mathrm{O}$-undersaturated conditions, Earth Planet. Sci. Lett., 248(3-4), 715-734, doi:10.1016/j.eps1.2006.06.014.

Hier-Majumder, S., I. M. Anderson, and D. L. Kohlstedt (2005), Influence of protons on $\mathrm{Fe}-\mathrm{Mg}$ interdiffusion in olivine, J. Geophys. Res., 110, B02202, doi:10.1029/ 2004JB003292.

Hirsch, L. M., T. J. Shankland, and A. G. Duba (1993), Electrical conduction and polaron mobility in Fe-bearing olivine, Geophys. J. Int., 114(1), 36-44, doi:10.1111/j.1365-246X. 1993.tb01464.x.

Hirschmann, M., and D. Kohlstedt (2012), Water in Earth's mantle, Phys. Today, 65(3), 40-45, doi:10.1063/PT.3.1476.

Hirth, G., and D. L. Kohlstedt (1996), Water in the oceanic upper mantle: Implications for rheology, melt extraction and the evolution of the lithosphere, Earth Planet. Sci. Lett., 144(1-2), 93-108, doi:10.1016/0012-821X(96)00154-9.

Huang, X. G., Y. S. Xu, and S. Karato (2005), Water content in the transition zone from electrical conductivity of wadsleyite and ringwoodite, Nature, 434(7034), 746-749, doi:10.1038/ nature 03426.

Ingrin, J., and H. Skogby (2000), Hydrogen in nominally anhydrous upper-mantle minerals: Concentration levels and implications, Eur. J. Mineral., 12(3), 543-570.

James, D. E., M. J. Fouch, J. C. VanDecar, S. van der Lee, and G. Kaapvaal Seismic (2001), Tectospheric structure beneath southern Africa, Geophys. Res. Lett., 28(13), 2485-2488, doi:10.1029/2000GL012578.
James, D. E., F. R. Boyd, D. Schutt, D. R. Bell, and R. W. Carlson (2004), Xenolith constraints on seismic velocities in the upper mantle beneath southern Africa, Geochem. Geophys. Geosyst., 5, Q01002, doi:10.1029/2003GC000551.

Jones, A. G. (1988), Static shift of magnetotelluric data and its removal in a sedimentary basin environment, Geophysics, 53(7), 967-978, doi:10.1190/1.1442533.

Jones, A. G. (1999), Imaging the continental upper mantle using electromagnetic methods, Lithos, 48(1-4), 57-80, doi:10.1016/S0024-4937(99)00022-5.

Jones, A. G., R. L. Evans, and D. W. Eaton (2009a), Velocityconductivity relationships for mantle mineral assemblages in Archean cratonic lithosphere based on a review of laboratory data and Hashin-Shtrikman extremal bounds, Lithos, 109(1-2), 131-143, doi:10.1016/j.lithos.2008.10.014

Jones, A. G., et al. (2009b), Area selection for diamonds using magnetotellurics: Examples from southern Africa, Lithos, 112, 83-92, doi:10.1016/j.lithos.2009.06.011.

Jones, M. Q. W. (1988), Heat flow in the Witwatersrand Basin and environs and its significance for the South African shield geotherm and lithosphere thickness, J. Geophys. Res. 93(B4), 3243-3260, doi:10.1029/JB093iB04p03243.

Jung, H., and S. Karato (2001), Water-induced fabric transitions in olivine, Science, 293(5534), 1460-1463, doi:10.1126/ science.1062235.

Karato, S. (1990), The role of hydrogen in the electrical conductivity of the upper mantle, Nature, 347(6290), 272-273, doi: $10.1038 / 347272 \mathrm{a} 0$.

Karato, S. (2006), Remote sensing of hydrogen in Earth's mantle, in Water in Nominally Anhydrous Minerals, Rev. in Mineral. and Geochem., vol. 62, edited by H. Keppler and J. R. Smyth, pp. 343-375, Mineral. Soc. of Am., Washington, D. C., doi:10.2138/rmg.2006.62.15.

Karato, S. (2011), Water distribution across the mantle transition zone and its implications for global material circulation, Earth Planet. Sci. Lett., 301(3-4), 413-423, doi:10.1016/j. epsl.2010.11.038.

Karato, S., and L. D. Dai (2009), Comments on "Electrical conductivity of wadsleyite as a function of temperature and water content" by Manthilake et al., Phys. Earth Planet. Inter., 174(1-4), 19-21, doi:10.1016/j.pepi.2009.01.011.

Karato, S., and D. Wang (2012), Electrical conductivity of minerals and rocks, in Physics and Chemistry of the Deep Earth, edited by S. Karato, John Wiley, Hoboken. N. J., in press.

Karato, S., M. S. Paterson, and J. D. Fitz Gerald (1986), Rheology of synthetic olivine aggregates: Influence of grain-size and water, J. Geophys. Res., 91(B8), 8151-8176, doi:10.1029/JB091iB08p08151.

Keppler, H., and J. R. Smyth (2006), Preface, in Water in Nominally Anhydrous Minerals, Rev. in Mineral. and Geochem., vol. 62, pp. v-viii, Mineral. Soc. of Am., Washington, D. C., doi:10.2138/rmg.2006.62.0.

Khan, A., and T. J. Shankland (2012), A geophysical perspective on mantle water content and melting: Inverting electromagnetic sounding data using laboratory-based electrical conductivity profiles, Earth Planet. Sci. Lett., 317-318, 27-43, doi:10.1016/j.eps1.2011.11.031.

Khan, A., A. Kuvshinov, and A. Semenov (2011), On the heterogeneous electrical conductivity structure of the Earth's mantle with implications for transition zone water content, J. Geophys. Res., 116, B01103, doi:10.1029/2010JB007458.

Kobussen, A. F., W. L. Griffin, and S. Y. O'Reilly (2009), Cretaceous thermo-chemical modification of the Kaapvaal 
cratonic lithosphere, South Africa, Lithos, 112, 886-895, doi:10.1016/j.lithos.2009.06.031.

Köhler, T., and G. P. Brey (1990), Calcium exchange between olivine and clinopyroxene calibrated as a geothermobarometer for natural peridotites from 2 to $60 \mathrm{~kb}$ with applications, Geochim. Cosmochim. Acta, 54, 2375-2388, doi:10.1016/ 0016-7037(90)90226-B.

Kurosawa, M., H. Yurimoto, and S. Sueno (1997), Patterns in the hydrogen and trace element compositions of mantle olivines, Phys. Chem. Miner., 24(6), 385-395, doi:10.1007/ s002690050052.

Kurszlaukis, S., L. Franz, and V. Lorenz (1998), On the volcanology of the Gibeon Kimberlite Field, Namibia, J. Volcanol. Geotherm. Res., 84(3-4), 257-272, doi:10.1016/S03770273(98)00044-4.

Li, Z. X. A., C. T. A. Lee, A. H. Peslier, A. Lenardic, and S. J. Mackwell (2008), Water contents in mantle xenoliths from the Colorado Plateau and vicinity: Implications for the mantle rheology and hydration-induced thinning of continental lithosphere, J. Geophys. Res., 113, B09210, doi:10.1029/ 2007JB005540.

Libowitzky, E., and G. R. Rossman (1997), An IR absorption calibration for water in minerals, Am. Mineral., 82(11-12), 1111-1115.

MacGregor, I. D. (1974), The system $\mathrm{MgO}-\mathrm{Al}_{2} \mathrm{O}_{3}-\mathrm{SiO}_{2}$ : Solubility of $\mathrm{Al}_{2} \mathrm{O}_{3}$ in enstatite for spinel and garnet peridotite compositions, Am. Mineral., 59, 110-119.

Mackwell, S. J., and D. L. Kohlstedt (1990), Diffusion of hydrogen in olivine: Implications for water in the mantle, J. Geophys. Res., 95(B4), 5079-5088, doi:10.1029/ JB095iB04p05079.

Mackwell, S. J., D. L. Kohlstedt, and M. S. Paterson (1985), The role of water in the deformation of olivine single crystals, J. Geophys. Res., 90(B13), 11,319-11,333, doi:10.1029/ JB090iB13p11319.

Manthilake, M., T. Matsuzaki, T. Yoshino, S. Yamashita, E. Ito, and T. Katsura (2009), Electrical conductivity of wadsleyite as a function of temperature and water content, Phys. Earth Planet. Inter., 174(1-4), 10-18, doi:10.1016/ j.pepi.2008.06.001.

Martin, R. F., and G. Donnay (1972), Hydroxyl in the mantle, Am. Mineral., 57(3-4), 554-570.

Meier, U., J. Trampert, and A. Curtis (2009), Global variations of temperature and water content in the mantle transition zone from higher mode surface waves, Earth Planet. Sci. Lett., 282(1-4), 91-101, doi:10.1016/j.eps1.2009.03.004.

Miensopust, M. P., A. G. Jones, M. R. Muller, X. Garcia, and R. L. Evans (2011), Lithospheric structures and Precambrian terrane boundaries in northeastern Botswana revealed through magnetotelluric profiling as part of the Southern African Magnetotelluric Experiment, J. Geophys. Res., 116, B02401, doi:10.1029/2010JB007740.

Mosenfelder, J. L., M. Le Voyer, G. R. Rossman, Y. B. Guan, D. R. Bell, P. D. Asimow, and J. M. Eiler (2011), Analysis of hydrogen in olivine by SIMS: Evaluation of standards and protocol, Am. Mineral., 96(11-12), 1725-1741, doi:10.2138/ am.2011.3810.

Muller, M. R., et al. (2009), Lithospheric structure, evolution and diamond prospectivity of the Rehoboth Terrane and western Kaapvaal Craton, southern Africa: Constraints from broadband magnetotellurics, Lithos, 112, 93-105, doi:10.1016/ j.lithos.2009.06.023.

Nimis, P., and H. Grutter (2010), Internally consistent geothermometers for garnet peridotites and pyroxenites,
Contrib. Mineral. Petrol., 159(3), 411-427, doi:10.1007/ s00410-009-0455-9.

O'Neill, H. S. C., and B. J. Wood (1979), An experimental study of $\mathrm{Fe}-\mathrm{Mg}$ partitioning between garnet and olivine and its calibration as a geothermometer, Contrib. Mineral. Petrol., 70, 59-70, doi:10.1007/BF00371872.

Parker, R. L. (1980), The inverse problem of electromagnetic induction: Existence and construction of solutions based on incomplete data, J. Geophys. Res., 85(B8), 4421-4428, doi:10.1029/JB085iB08p04421.

Parker, R. L., and J. R. Booker (1996), Optimal onedimensional inversion and bounding of magnetotelluric apparent resistivity and phase measurements, Phys. Earth Planet. Inter., 98(3-4), 269-282, doi:10.1016/S0031-9201(96) 03191-3.

Paterson, M. S. (1982), The determination of hydroxyl by infrared absorption in quartz, silicate glasses and similar materials, Bull. Mineral., 105(1), 20-29.

Peslier, A. H. (2010), A review of water contents of nominally anhydrous natural minerals in the mantles of Earth, Mars and the Moon, J. Volcanol. Geotherm. Res., 197(1-4), 239-258, doi:10.1016/j.jvolgeores.2009.10.006.

Peslier, A. H., A. B. Woodland, and J. A. Wolff (2008), Fast kimberlite ascent rates estimated from hydrogen diffusion profiles in xenolithic mantle olivines from southern Africa, Geochim. Cosmochim. Acta, 72(11), 2711-2722, doi:10.1016/ j.gca.2008.03.019.

Peslier, A. H., A. B. Woodland, and M. Lazarov (2010a), Controls of $\mathrm{H}$ incorporation in pyroxenes and garnets from FTIR data on Kaapvaal craton xenoliths, Geochim. Cosmochim. Acta, 74(12), A808.

Peslier, A. H., A. B. Woodland, D. R. Bell, and M. Lazarov (2010b), Olivine water contents in the continental lithosphere and the longevity of cratons, Nature, 467(7311), 78-81, doi:10.1038/nature09317.

Poe, B. T., C. Romano, F. Nestola, and J. R. Smyth (2010), Electrical conductivity anisotropy of dry and hydrous olivine at $8 \mathrm{GPa}$, Phys. Earth Planet. Inter., 181(3-4), 103-111, doi:10.1016/j.pepi.2010.05.003.

Romano, C., B. T. Poe, N. Kreidie, and C. A. McCammon (2006), Electrical conductivities of pyrope-almandine garnets up to $19 \mathrm{GPa}$ and $1700^{\circ} \mathrm{C}$, Am. Mineral., 91(8-9), 1371-1377, doi:10.2138/am.2006.1983.

Rossman, G. R. (2006), Analytical methods for measuring water in nominally anhydrous minerals, in Water in Nominally Anhydrous Minerals, Rev. in Mineral. and Geochem., vol. 62, edited by H. Keppler and J. R. Smyth, pp. 1-28, Mineral. Soc. of Am., Washington, D. C., doi:10.2138/ rmg.2006.62.1.

Salje, E. K. H. (2007), An empirical scaling model for averaging elastic properties including interfacial effects, $\mathrm{Am}$. Mineral., 92(2-3), 429-432, doi:10.2138/am.2007.2472.

Schmädicke, E., M. Okrusch, P. Rupprecht-Gutowski, and T. M. Will (2011), Garnet pyroxenite, eclogite and alkremite xenoliths from the off-craton Gibeon Kimberlite Field, Namibia: A window into the upper mantle of the Rehoboth Terrane, Precambrian Res., 191(1-2), 1-17, doi:10.1016/ j.precamres.2011.07.010.

Smith, C. B. (1983), Pb- Sr and Nd-isotopic evidence for the source regions of southern African Cretaceous kimberlites, Nature, 304, 51-54, doi:10.1038/304051a0.

Spratt, J. E., A. G. Jones, V. A. Jackson, L. Collins, and A. Avdeeva (2009), Lithospheric geometry of the Wopmay orogen from a Slave craton to Bear Province magnetotelluric 
transect, J. Geophys. Res., 114, B01101, doi:10.1029/ 2007JB005326.

Suetsugu, D., T. Inoue, A. Yamada, D. Zhao, and M. Obayashi (2006), Towards mapping three-dimensional distribution of water in the transition zone from $\mathrm{P}$ wave velocity tomography and 660-km discontinuity depths, in Earth's Deep Water Cycle, edited by S. D. Jacobsen and S. van der Lee, pp. 237-249, AGU, Washington, D. C., doi:10.1029/ $168 \mathrm{GM} 18$.

Sundvall, R., and R. Stalder (2011), Water in upper mantle pyroxene megacrysts and xenocrysts: A survey study, Am. Mineral., 96(8-9), 1215-1227, doi:10.2138/am.2011.3641.

ten Grotenhuis, S. M., M. R. Drury, C. J. Peach, and C. J. Spiers (2004), Electrical properties of fine-grained olivine: Evidence for grain boundary transport, J. Geophys. Res., 109, B06203, doi:10.1029/2003JB002799.

Thomas, S. M., M. Koch-Muller, P. Reichart, D. Rhede, R. Thomas, R. Wirth, and S. Matsyuk (2009), IR calibrations for water determination in olivine, $\mathrm{r}-\mathrm{GeO}_{2}$, and $\mathrm{SiO}_{2}$ polymorphs, Phys. Chem. Miner., 36(9), 489-509, doi:10.1007/ s00269-009-0295-1.

Thompson, A. B. (1992), Water in the Earth's upper mantle, Nature, 358(6384), 295-302, doi:10.1038/358295a0.

Wang, D. J., M. Mookherjee, Y. S. Xu, and S. Karato (2006), The effect of water on the electrical conductivity of olivine, Nature, 443(7114), 977-980, doi:10.1038/nature05256.

Watson, H. C., J. J. Roberts, and J. A. Tyburczy (2010), Effect of conductive impurities on electrical conductivity in polycrystalline olivine, Geophys. Res. Lett., 37, L02302, doi:10.1029/2009GL041566.

Williams, Q., and R. J. Hemley (2001), Hydrogen in the deep earth, Annu. Rev. Earth Planet. Sci., 29, 365-418, doi:10.1146/ annurev.earth.29.1.365.

Xia, Q. K., Y. T. Hao, P. Li, E. Deloule, M. Coltorti, L. Dallai, X. Z. Yang, and M. Feng (2010), Low water content of the Cenozoic lithospheric mantle beneath the eastern part of the North China Craton, J. Geophys. Res., 115, B07207, doi:10.1029/2009JB006694.
Xu, X. F. (2011), On the third-order bounds of the effective shear modulus of two-phase composites, Mech. Mater., 43(5), 269-275, doi:10.1016/j.mechmat.2011.02.009.

Xu, Y. S., and T. J. Shankland (1999), Electrical conductivity of orthopyroxene and its high pressure phases, Geophys. Res. Lett., 26(17), 2645-2648, doi:10.1029/1999GL008378.

Xu, Y. S., T. J. Shankland, and B. T. Poe (2000), Laboratorybased electrical conductivity in the Earth's mantle, J. Geophys. Res., 105(B12), 27,865-27,875, doi:10.1029/2000JB900299.

Yang, X. Z., and C. McCammon (2012), $\mathrm{Fe}_{3}^{+}$-rich augite and high electrical conductivity in the deep lithosphere, Geology, 40(2), 131-134, doi:10.1130/G32725.1.

Yang, X. Z., H. Keppler, C. McCammon, H. W. Ni, Q. K. Xia, and Q. C. Fan (2011), Effect of water on the electrical conductivity of lower crustal clinopyroxene, J. Geophys. Res., 116, B04208, doi:10.1029/2010JB008010.

Yang, X. Z., H. Keppler, C. McCammon, and H. W. Ni (2012), Electrical conductivity of orthopyroxene and plagioclase in the lower crust, Contrib. Mineral. Petrol., 163(1), 33-48, doi:10.1007/s00410-011-0657-9.

Yoshino, T. (2010), Laboratory electrical conductivity measurement of mantle minerals, Surv. Geophys., 31(2), 163-206, doi:10.1007/s10712-009-9084-0.

Yoshino, T., and T. Katsura (2009), Reply to comments on "Electrical conductivity of wadsleyite as a function of temperature and water content" by Manthilake et al, Discussion, Phys. Earth Planet. Inter., 174(1-4), 22-23, doi:10.1016/j. pepi.2009.01.012.

Yoshino, T., T. Matsuzaki, S. Yamashita, and T. Katsura (2006), Hydrous olivine unable to account for conductivity anomaly at the top of the asthenosphere, Nature, 443(7114), 973-976, doi:10.1038/nature05223.

Yoshino, T., T. Matsuzaki, A. Shatskiy, and T. Katsura (2009), The effect of water on the electrical conductivity of olivine aggregates and its implications for the electrical structure of the upper mantle, Earth Planet. Sci. Lett., 288(1-2), 291-300, doi:10.1016/j.eps1.2009.09.032. 